\title{
More than an urban legend: the short- and long-run effects of unplanned fertility shocks
}

\author{
Thiemo Fetzer $^{1}$ (D) . Oliver Pardo ${ }^{2}$. \\ Amar Shanghavi ${ }^{3}$
}

Received: 16 February 2017 / Accepted: 28 December 2017 / Published online: 6 February 2018 (C) The Author(s) 2018. This article is an open access publication

\begin{abstract}
This paper examines the short- and long-run effects of a quasi-exogenous variation in fertility behavior due to a yearlong period of power rationing in Colombia in 1992. We show that power shortages caused a mini baby boom and that the increase in fertility was unplanned and persistent: the time in between births was reduced and overall lifetime fertility increased. We also present evidence suggesting that women who had a baby due to the outage found themselves in worse socioeconomic conditions 12 years later.
\end{abstract}

Keywords Fertility $\cdot$ Infrastructure $\cdot$ Natural experiment · Unplanned parenthood

JEL Classification $\mathrm{J} 13 \cdot \mathrm{J} 16 \cdot \mathrm{O} 18 \cdot \mathrm{H} 41$

\section{Introduction}

The idea of baby booms following a blackout has been a subject of contention for a long time. It first came to prominence in popular culture after the great New York City blackout of 1965, which left over 30 million people without electricity for $13 \mathrm{~h}$. However, the seminal work by Udry (1970) concluded that birthrates did not increase

Responsible editor: Junsen Zhang

Thiemo Fetzer

thiemo.fetzer@gmail.com

1 University of Warwick, Coventry, UK

2 Pontificia Universidad Javeriana, Bogotá, Colombia

3 Tamu Tamu Tanzania LTD, Dar es Salaam, Tanzania 
significantly 9 months after this event. Since then, the theory has been termed an "urban legend" by the president of the Population Association of America. ${ }^{1}$

Unlike power outages in the developed world, blackouts are commonplace in developing countries. Many of them experience rolling blackouts that last weeks, if not months, and for several hours a day. However, the existing literature has almost exclusively focused on the costs to firms and investment from unreliable public infrastructure (see Fisher-Vanden et al. 2015; Reinikka and Svensson 2002). This paper is among the first to highlight both the short- and long-run effects of unreliable power infrastructure on household fertility and socioeconomic outcomes.

We shed light on three interrelated issues. First, we provide evidence that, in the short run, power rationing does, in fact, create baby booms. Second, we answer the question: how persistent is this shock on fertility? We check the claim that after having an unplanned baby, women maintain the size of family they originally desired by having fewer children in the future (Ward and Butz 1980; Barmby and Cigno 1990). Third, we address the long-run effects of the fertility shock as measured by socioeconomic outcomes like educational attainment (Ribar 1994, 1999; Geronimus and Korenman 1993; Ashcraft et al. 2013), participation in the labor market (Angrist and Evans 1998; Gangadharan et al. 1999), and child health (Burlando 2014b) 12 years after the shock.

We exploit a unique natural experiment set in Colombia to address these questions. In 1992, the El Niño climate phenomena caused a drought, which led to such low water levels in rivers and reservoirs that power generation plummeted, resulting in daily electricity rationing over the period from March 1992 to March 1993. ${ }^{2}$ This constitutes a natural experiment with quasi-random treatment appealing at two levels. First, the yearlong power rationing gives us sufficient statistical power to detect even minor effects. Second, the power rationing was heterogeneous across Colombia. We exploit this spatial variation in the intensity of power rationing to study how shortand long-term fertility rates varied accordingly.

We do so by constructing a retrospective mother-level birth history using the micro sample of the 2005 population census of Colombia. This provides us with the number of birth events. We combine this with the municipality-level variation in the intensity of the power rationing. This measure of treatment intensity is constructed from nighttime lights satellite imagery. We use this dataset to study the impact of power rationing, both in the short run (the first year following the blackout period) and the long run (12 years after the end of the blackout).

For the short-run analysis, we adopt a fixed effects model. By looking at the impact of the blackout on the fertility of individual mothers, we are able to address concerns of omitted time-invariant variables. We show that women, on average, experienced a $4 \%$ increase in the probability of giving birth in 1993, the year following the blackout. This implies that more babies were conceived during 1992, the year in which power

\footnotetext{
${ }^{1}$ https://today.duke.edu/2004/05/blackout_0504.html.

${ }^{2}$ It is well understood that El-Niño and resulting water deficiencies can affect electricity generation in countries that heavily rely on hydropower as has been seen recently in Venezuela, which had to significantly ration electricity for 3 months in response to the 2016 El Niño cycle.
} 
was rationed. A back-of-the-envelope calculation suggests that the blackout led to an additional $1.9 \%$ of births_-representing around 6,800 babies-in 1993.

Next, we show that women do not respond to this short-term fertility boost by having fewer children later. Using the 2005 census cross section, we estimate the effect of the blackout on the number of children a woman has 12 years after the end of the blackout. We take advantage of the fact that women who gave birth during 1992 may have been exposed to the power rationing, but were biologically much less likely to conceive because they had just delivered a baby. For the estimation, we use a difference-in-difference approach. In the first difference, we compare women who gave birth in 1993 in blackout areas with women who gave birth in 1993 in non-blackout areas. For the second difference, we compare women who gave birth in 1992 in blackout areas with women who gave birth in 1992 in non-blackout areas. The difference between these differences corresponds to our estimate of the long-run effect of the blackout on fertility.

We estimate that women who had a child in 1993 due to the blackout had, on average, 0.07 more children in 2005. This estimate implies that in 2005, there were approximately 14,100 more children as a consequence of the blackout. Therefore, the fertility shock had not yet been offset 12 years later. In addition, we find that, for women who had already given birth at least once prior to the power outage, the blackout reduced the time between births by 1 to 2 months. This further supports our interpretation that the power outage-induced fertility increase was unplanned.

Finally, we document the long-run effects of the blackout on some socioeconomic characteristics of women (and to some extent their children) by applying the same difference-in-difference approach. Our research design allows us to rule out some potential confounders such as the impact of the blackout on job loss or other income shocks, since both women who gave birth in 1992 and 1993 may have been exposed to the power outage (and a possible income shock), but women who gave birth in 1992 could not physically conceive that same year. We show that the two sets of women are very similar on a set of predetermined exogenous socioeconomic characteristics. Further, we find patterns that are consistent with our interpretation that women who had an unplanned baby due to the outage find themselves in worse socioeconomic conditions. We think that the evidence presented provides some support for our overall interpretation that we capture genuine long-run effects as opposed to purely measuring selection into treatment of vulnerable populations.

This paper contributes to several strands of literature. It relates closely to Burlando (2014a), as he studies the impact of a month-long power outage in Zanzibar on village-level fertility outcomes. He finds a $20 \%$ increase in village-level births 9 months after the blackout, but cannot provide any further evidence as to whether this temporary increase was dynamically offset. More generally, our paper contributes to a growing empirical literature on examining the impact of electricity infrastructure in developing countries (see Gerard and Costa 2015; Dinkelman 2011; Rud 2012). The paper also relates to understanding the fertility response to other aggregate shocks. Evans et al. (2008), Pörtner (2008) and Oliveira and QuintanaDomeque (2016) examine the effect of natural disasters and hurricanes in particular on fertility and birth outcomes. Aragón and Rud (2016) study the exposure to air pollution and infant mortality using micro-data stemming from one million birth events. 
Burlando (2014b) looks at mothers' exposure to power outages during pregnancy and finds that this resulted in lower birth weights. ${ }^{3}$ Bozzoli and Quintana-Domeque (2014) study the impact of the economic crisis in Argentina on birth weights, while (Quintana-Domeque and Ródenas-Serrano 2014) explore the impact of in uteroexposure to stress caused by terrorism attacks in Spain on birth weight. Schindler and Brück (2011) examine the effect of conflict on the fertility choices of survivors, finding that loss of siblings only has a short-term effect on reproductive behavior. Our study also speaks to the literature on the influence of culture, media, and leisure on fertility (Ferrara et al. 2012; Jensen and Oster 2009; Kearney and Levine 2015). These studies have found a link between television programming and fertility behavior, including smaller family size. Finally, we make significant contributions on the methodological front by being the first to exploit nighttime light data to detect power outages from outer space and combine this data with individual-level birth records.

The rest of the paper proceeds as follows. Section 2 provides a brief background and context for the 1992 blackout in Colombia. Section 3 describes the data and how we constructed our main dependent variables. Section 4 provides the empirical strategy, while Section 5 presents the key results. The conclusion follows in Section 6.

\section{Context}

Colombia is a useful and interesting case to study in the context of developing countries, as its fertility patterns were very similar in 1992 to the rest of Latin America and the Caribbean. Fertility rates (births per women) in 1992 were 2.86 in Colombia and 3.06 in Latin America and the Caribbean. Similarly, population growth rates in 1992 were $1.8 \%$ in both Colombia and the region. ${ }^{4}$ Thus, from an economic and demographic point of view, Colombia serves as a good case study for developing countries.

Colombia gets most of its electricity supply from hydroelectric sources. Installed capacity of electricity in 1991 was $78 \%$ hydraulic and $22 \%$ thermal. ${ }^{5}$ In 1992 , about $40 \%$ of hydroelectric power was produced in fourteen hydroelectric power plants located mainly in the Caldas and Antioquia departments of central Colombia. ${ }^{6} \mathrm{~A}$ large share of the power-generating capacity comes from so-called run-of-the-river power plants, sited along a river or between two rivers, with water for power generation turbines being supplied by the river's natural flow. Therefore, this type of power plant is particularly vulnerable to reductions in water flows, as shown by the tight correlation between power production from hydro plants and rainfall deficiency in Fig. 1.

\footnotetext{
${ }^{3}$ Studies have found that low birth weight correlates with worse life time outcomes. See for example (Bozzoli et al. 2009).

${ }^{4}$ http://data.worldbank.org/country/Colombia and http://data.worldbank.org/region/latin-america-andcaribbean

${ }^{5}$ UPME, Boletin Estadistico de Minas y Energia 1990-2010, http://www.simco.gov.co/LinkClick.aspx? fileticket=ABaDJv5Q1Jo=.

${ }^{6}$ Department of Energy, An Energy Overview of Colombia, http://goo.gl/nnhWBN.
} 


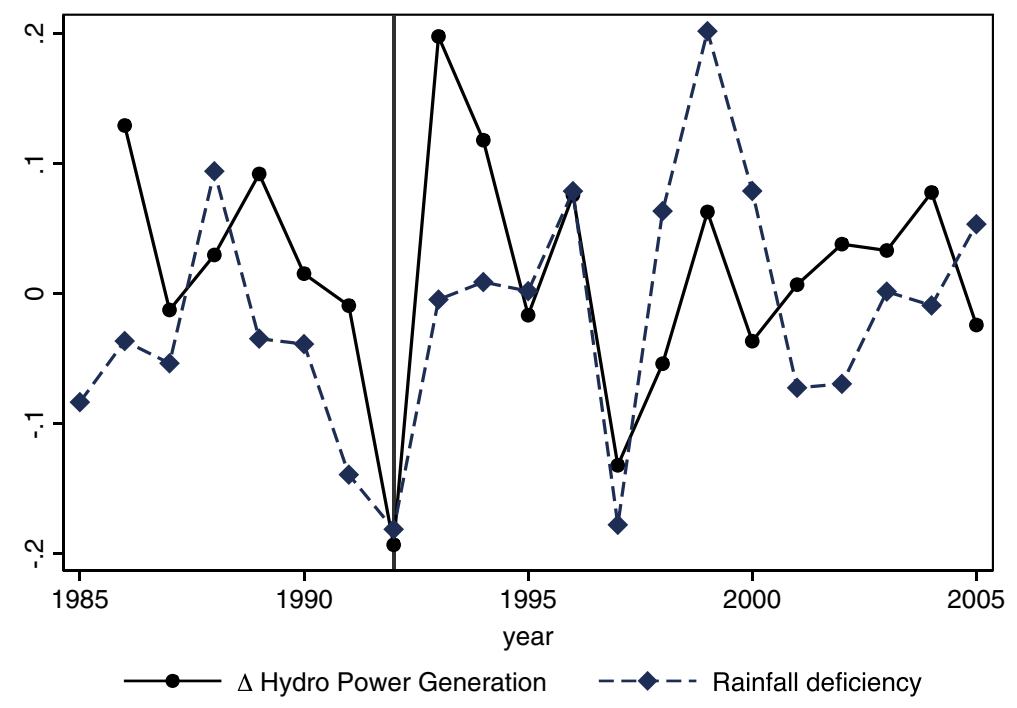

Fig. 1 This figure plots the year-on-year proportional change in estimated hydropower generation for Colombia (solid line) and the proportional rainfall deficiency compared to long-term means (dashed line). Data on hydro power generation from the World Bank

By the end of 1991, the meteorological phenomenon of El Niño reappeared in the Pacific. ${ }^{7}$ In Colombia, this led to a dramatic depletion of the river flows and reservoirs that fed most of the major power plants. Between 1991 and 1993, water availability for power generation was, on average, $14.2 \%$ lower compared to the long-term average. In the peak months of 1992, water availability was $42.8 \%$ lower than the long-term average. ${ }^{8}$ As a result, some power stations needed to cut back production dramatically because of the steep decline in water availability. One of the biggest energy firms estimated that throughout the year, there was a shortfall equivalent to roughly $20 \%$ of the annual production of $1991 .^{9}$

On the 28th of February 1992, the government announced a nationwide power rationing, starting the 2 nd of March. It was announced that rationing would be at most "for a couple of hours [per day], [lasting] no more than three months". On the 5th of March, the government acknowledged that rationing might be necessary for up to a year. On the 14th of March, rationing was extended to industrial areas that had previously been excluded. Eventually, the rationing lasted up to $9 \mathrm{~h} /$ day in the capital Bogotá, but could last for up to $12 \mathrm{~h}$ /day in other cities. Over the year, rationing waxed and waned depending on rainfall levels, ultimately rendering the continued

\footnotetext{
${ }^{7}$ See Appendix Fig. 8.

${ }^{8}$ UPME, Boletin Estadistico de Minas y Energia 1990-2010, http://www.simco.gov.co/LinkClick.aspx? fileticket $=\mathrm{ABaDJv} 5 \mathrm{Q} 1 \mathrm{Jo}=$.

${ }^{9}$ See http://www.tebsa.com.co/history.htm, accessed on 20.06.2013.
} 
extent of rationing an exogenous factor. The rationing finally ended on the 1st of April of $1993 .^{10}$

Colombians throughout the country felt the impacts of the extended rationing, which is why the period from 1992 to 1993 is referred to by Colombians simply as "The Blackout". It forced Colombians to change their habits. Daylight Savings Time (DST) was introduced to take advantage of daylight. Unable to function without electricity, factories and other workplaces sent workers home early. TV business suffered because prime viewing times coincided with rationing hours. Pointing out a supposed tradeoff between time spent watching TV and fertility rates, a commentator wrote at the time: "With these blackouts, family romps will increase the number of Colombians produced in the dark". ${ }^{11}$

The power rationing, though, was not evenly spread across the country. In the northeast, thermal power generated from coal has been historically available. In the south, some regions were barely connected to the national electricity grid. Further, electricity losses along transmission lines generate a natural gradient. All these factors contributed to create spatial variation in the intensity of the power rationing, which we exploit in this paper. ${ }^{12}$

\section{Data}

\subsection{Detecting power outages from remote sensing}

To the best of our knowledge, this is the first paper to use nighttime light data to study the exposure to power outages at the regional level. ${ }^{13}$ Figure 2 highlights our approach to measuring power rationing indirectly, using nighttime luminosity data available from the US Defense Meteorological Satellite Program (DMSP). The figure depicts the luminosity variable around three main urban centers in Colombia in 1992 (left) and 1993 (right). The northern area is the Medellín metropolitan area, while in the south is Colombia's third largest city, Cali. The concentration of light to the right is the metropolitan area of Bogotá. The differences in the pictures are dramatic. Especially around Bogotá, the broader geographic area appears to have been dark in 1992, while it was lit in 1993.

Note that the nighttime light data series is only available from 1992 onward. Hence, we cannot compare the intensity of light in 1992 (the year of the outage) with preceding years, as these data simply do not exist. However, we may be able to compare the intensity of light in 1992 with that of 1993 or 1994. For this purpose,

\footnotetext{
${ }^{10}$ Appendix Table 9 summarizes the key events. For a detailed timeline, visit http://www.eltiempo.com/ archivo/documento/MAM-616547.

${ }^{11}$ See http://www.eltiempo.com/archivo/documento/MAM-123186, accessed on 08.08.2015.

${ }^{12}$ This is akin to Gerard and Costa (2015), who study the long-run effects of power rationing in the south of Brazil due to power production shortages following droughts in 2001. In their context, the lack of integration in the power network created distinct spatial variation in the extent of power rationing.

${ }^{13}$ Economists have used this data source to map economic activity (Doll 2008), economic growth (Henderson et al. 2012), agglomeration clusters (Storeygard 2015; Fetzer et al. 2016), and favoritism in the provision of public goods (Hodler and Raschky 2014).
} 

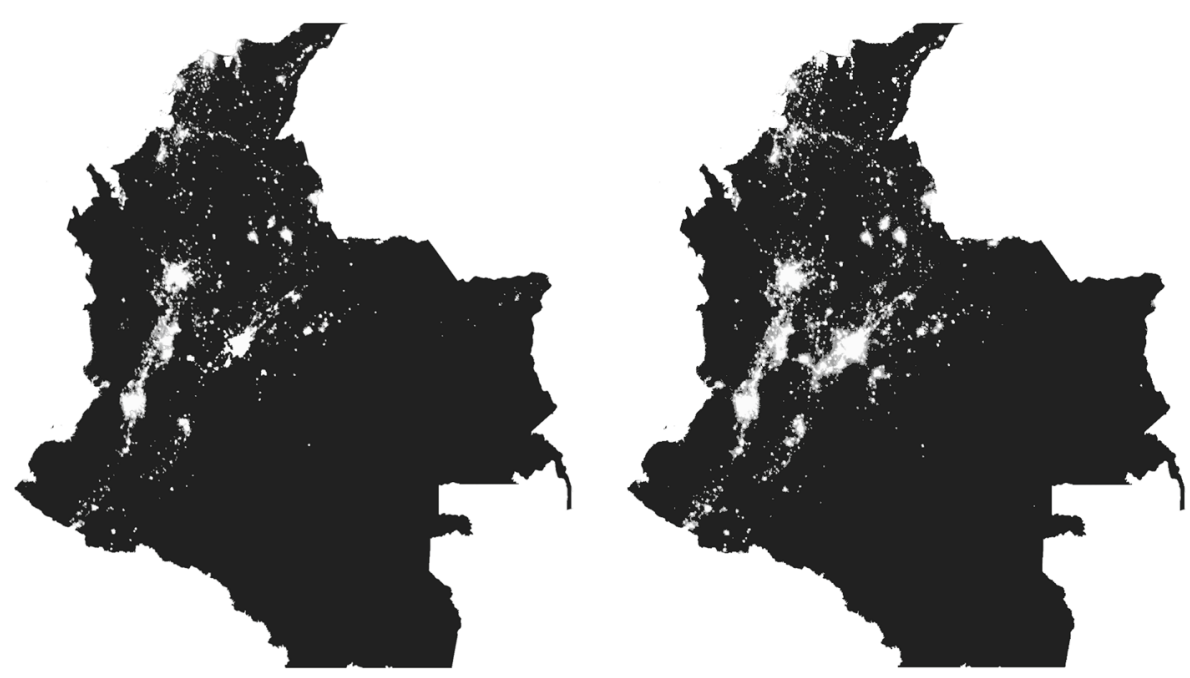

Fig. 2 Light Intensity in Colombia, 1992 (left) and 1993 (right) on identical log-scales along with municipality borders

we construct the average population-weighted municipality luminosity for the years 1992 and 1993. ${ }^{14}$ Then, for each municipality $m$, we construct the following power outage intensity variable:

$$
O_{m}=100 \times\left(1-\frac{\text { Light }_{m, 1992}}{\text { Light }_{m, 1993}}\right)
$$

Though the 1993 luminosity is an outcome variable in itself, it is hard to believe that the micro mother-level variation we exploit has a direct effect on 1993 luminosity. Nevertheless, this measure of outage contains a significant amount of noise. ${ }^{15}$ This is illustrated in Fig. 3, where we plot kernel densities of the outage distribution across our sample. Though the median is positive, there is a significant fraction of observations where the outage measure suggests increased luminosity in 1992 (the year of the blackout) as compared to 1993. The presence of noise is confirmed in the same figure by looking at the distribution of a placebo outage intensity defined by the 1993 to 1994 luminosity ratio. Though the mass concentrates around 0 , as it should be given that in 1993 and 1994, there were no shocks on power generation, the dispersion suggests that the measure $O_{m}$ contains a lot of noise.

In order to reduce the amount of noise in the luminosity data (and for ease of interpretation of estimated coefficients), we work throughout with a dummy variable equal to one for the case where the power rationing is above the median in our sample.

\footnotetext{
${ }^{14}$ See Appendix A.1 for more details on the data and its construction.

${ }^{15}$ We work throughout with the stable light version of the images that removes known sources of measurement errors such as, e.g., natural gas flaring. Nevertheless, since the satellites were not designed to pick up human induced luminosity, there is significant measurement error remaining (see Elvidge et al. 2004). We discuss this in Appendix A.1.
} 


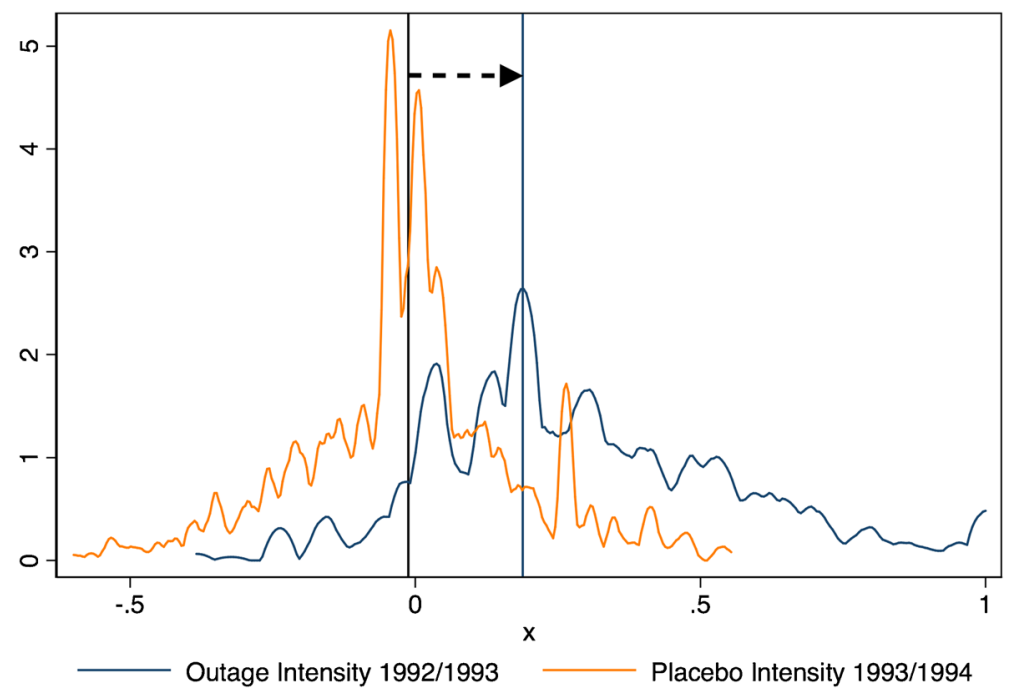

Fig. 3 This figure plots the distribution of the power rationing intensity measure in the balanced sample of mothers. The orange kernel density is a placebo outage measure computed for the years 1993 to 1994, in which there was no power rationing. Unsurprisingly, the distribution is centered around zero. The spread indicates that there is significant measurement error. The distribution of the outage measure between 1992 and 1993 is clearly shifted to the right, indicating that there were significantly lower levels of nighttime light emissions in 1992 relative to 1993. We use this to proxy for the extent of power rationing. The vertical line indicates the median power outage intensity

In particular, for every municipality $m$, we define $D_{m}$ as

$$
D_{m}=\mathbf{I}\left(O_{m}>\text { Median }\right)
$$

where $\mathbf{I}$ is the indicator function.

Figure 4 motivates the choice of the median as a cutoff. In this figure, we present the heterogeneous effect of power rationing intensity on the probability of a mother giving birth in 1993 by intensity decile. It is clear that municipalities with power rationing above the median are driving the effect. Results with a continuous measure of intensity are very similar throughout, but estimated with less precision. These results are presented in Appendix Tables 10, 12, and 13. The results are also very similar when using alternative plausible cutoffs.

The elasticity between luminosity and electricity consumption is between 0.9 and 1.1, as reported by Proville et al. (2017) and the original work of Elvidge et al. (1997). This suggests that a $1 \%$ drop in luminosity corresponds to a similar $1 \%$ drop in electricity consumption. In our sample, the mean outage intensity is $24 \%$, while the median outage intensity is around $18 \%$. This suggests that the median municipality saw a reduction in electricity consumption by around $18 \%$. This coincides with the shortfall of around $20 \%$ relative to the annual electricity production in 1991 reported by Tebsa, a big power generator at the time. ${ }^{16}$

\footnotetext{
${ }^{16}$ See http://www.tebsa.com.co/history.htm, accessed on 20.06.2013.
} 


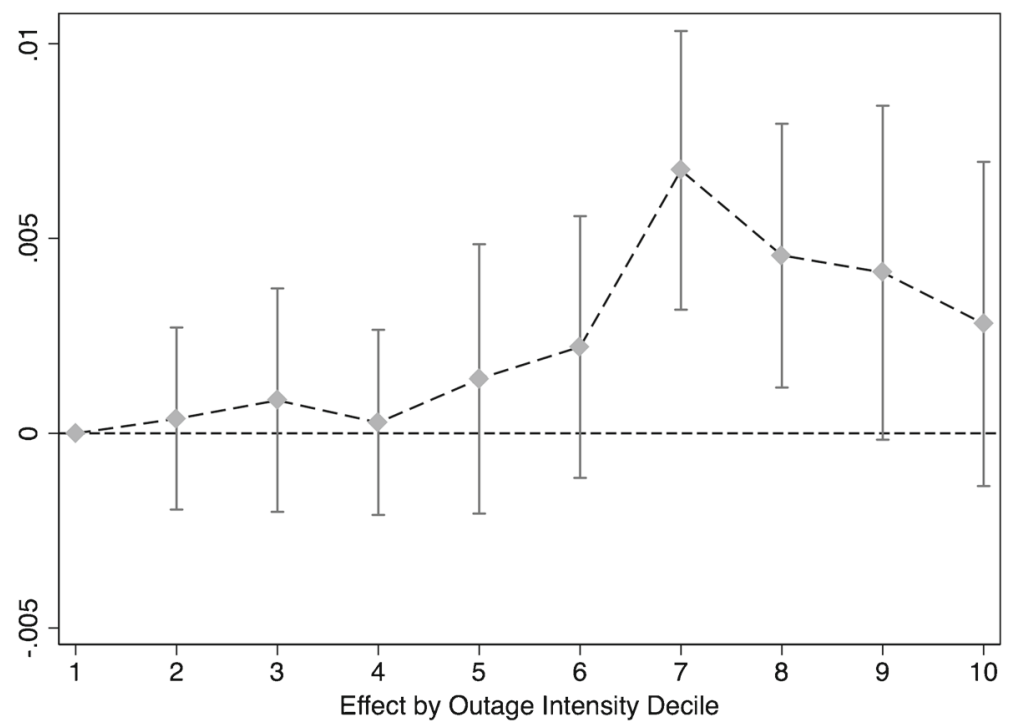

Fig. 4 This figure presents the heterogenous effect of power rationing intensity on the probability of a mother giving birth in 1993 by intensity decile, while controlling for mother and year fixed effects. The effect is driven by municipalities with above-median power rationing. $95 \%$ confidence bands obtained from clustering at the municipality level are indicated

We focus on urban populations to avoid confusing electrification with power rationing. In 1990, 96\% of the urban population had electricity, compared to around $51 \%$ of the rural population (World Bank Development Indicators 2011). Nevertheless, the results including the rural population are quite similar and are available in Appendix Tables 14, 15, 16, 17, and 18.

\subsection{Census data}

An analysis that studies fertility effects at the aggregate level may fail to discover any statistical effect due to low power conjoint with small effect sizes. In addition, there may be compositional effects as the cohorts of women who have babies in a municipality changes over time. In order to address this, we construct individuallevel birth histories using the 2005 micro sample census of Colombia provided by IPUMS. The micro-data sample covered $10 \%$ of the population at the time and has been hailed as the most successfully conducted population census in Colombia. ${ }^{17} \mathrm{We}$ construct a retrospective panel of mothers using the matched mother to children data for the period 1989 to $1996 .^{18}$

For the analysis on fertility choices around the outage event, our outcome variable is a dummy variable indicating whether a woman gave birth in a given year. We restrict our analysis to women born between 1948 and 1978, resulting in a cohort

\footnotetext{
${ }^{17}$ See http://unstats.un.org/unsd/censuskb20/KnowledgebaseArticle10236.aspx, accessed 20.06.2013.

${ }^{18}$ More details about the census data and possible alternative data can be found in Appendix A.2.
} 


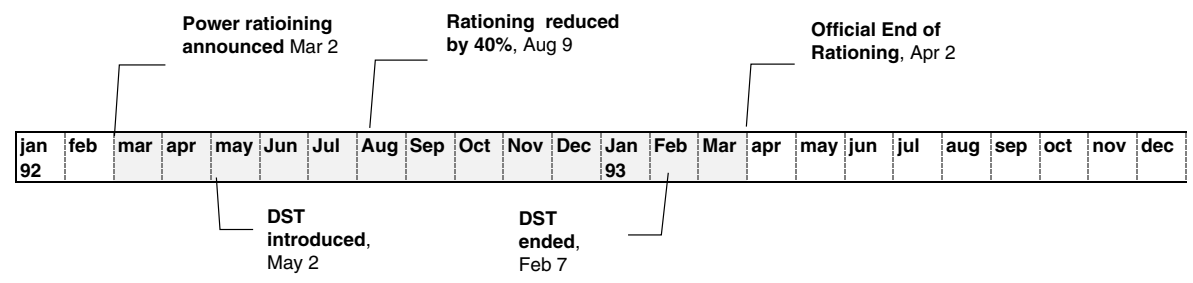

Treatment Definitions

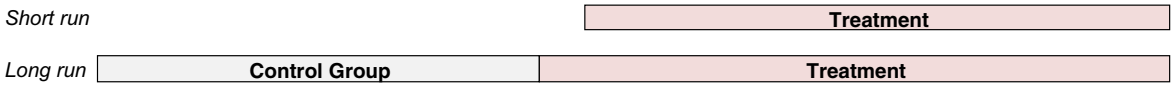

Fig. 5 Timeline of major events during the period of power rationing in 1992-1993 in Colombia, along with the treatment and control definitions for the short and long-run analysis

aged between 15 and 45 in $1993 .{ }^{19}$ The choice for the birth year cutoff ensures that we only include women considered to be of reproductive age in the year of treatment, consistent with the definition used by the well-known Demographic Health Surveys. Further, any other age cutoff does not affect our results once we consider mother fixed effects. This is because the variation comes from within a mother rather than across mothers. The panel structure of the data allows us to identify the effect of the blackout by exploiting within-mother variation in the timing of birth, instead of solely relying on spatial cross-region or within-region variation. This gives us a total number of 457,312 women with 288,600 children born in this period.

Figure 5 presents the timeline of the power-rationing period from 1992 to 1993. Power rationing began in March 1992 and ended 1 year later in the beginning of April 1993. Since pregnancy usually lasts 9 months, we define the treatment as our power-rationing measure multiplied by an indicator for the year 1993. This generates a small overlap since some of the births in December 1992 could have been due to the power rationing that commenced 9 months earlier. Nevertheless, we stick with 1993 as the treatment year, since the bulk of the effect should be captured in 1993. In fact, we will confirm this in the data.

For the long-run analysis, we construct a total births variable using the matched mother and child data based on the 2005 census. We restrict our analysis to comparing women who delivered during the first 9 months of the rationing period (hence unable to get pregnant during the blackout) with women who gave birth 9 months after any month of the rationing period (see Fig. 5). This leaves us with 22,347 and 40,256 women in each set, respectively. Fertility is measured as the number of children living with their mother. ${ }^{20}$

\footnotetext{
${ }^{19}$ The distribution of women by age group is presented in Appendix Fig. 9.

${ }^{20}$ We obtain very similar results using self-reported births after removing outliers (women with more than 10 children). The results are presented in Appendix Table 19.
} 


\section{Empirical strategy}

We separate the empirical analysis into three steps. First, we look at the short-run implications of the power outages on mother-level fertility. Second, we show that these effects persisted, i.e., that the power outage is associated with a lifelong increase in fertility. Third, we ask how this long-run effect correlates with the economic outcomes of the mothers (and their respective children) and try to make the case that we are capturing an effect that goes beyond selection.

\subsection{Short-term fertility effects}

To study fertility in the short run, our dependent variable is a dummy variable $B_{i m t}=$ 1 , if mother $i$ from municipality $m$ gave birth in year $t$. We estimate the following linear probability model:

$$
B_{i m t}=a_{i}+b_{t}+\gamma \times D_{m} \times Z_{t}+\epsilon_{i m t}
$$

where we include mother fixed effects $a_{i}$ and time fixed effects $b_{t}$. We add the subindex $m$ for municipality since the treatment intensity is fixed at municipality level. The dummy $Z_{t}$ equals one for $t=1993$, i.e., the year in which babies conceived in 1992 were born. ${ }^{21}$ Note that $Z_{t}$ is perfectly collinear with the time-fixed effects $b_{t}$ and that $D_{m}$ is invariant at the municipality level and thus perfectly collinear with the mother fixed effects $a_{i}$.

The coefficient of interest is $\gamma$, which measures the difference in the probability of giving birth in 1993 for women in municipalities that experienced rationing above the median. The interaction term exploits variation across municipalities by comparing mothers who experienced a blackout to mothers who did not. The coefficient $\gamma$ represents the causal effect of power-rationing on the probability of giving birth under the following identifying assumption: After controlling for mother fixed effects and exogenous covariates, the changes in probability of birth for mothers living in municipalities that experienced outages below the median provide a counterfactual for mothers living in municipalities that experienced outages above the median.

Municipality unobserved characteristics could be a source of violation of the identifying assumption in (1). We address this by exploiting within-mother variation over time. The inclusion of mother fixed effects helps us control for time-invariant characteristics both at the mother level (such as education and family background) and at the aggregate level (such as geography, history, and local culture). This can be thought of as an improvement over existing work, which typically studies fertility aggregated at some spatial level data. This can mask differences in the socioeconomic composition across different subpopulations (see Burlando 2014a). We further add various other demanding time effects interacted with baseline characteristics and add municipality-level trends to alleviate concerns about omitted time-varying factors driving the result. Further, we show that fertility in 1993 clearly spikes in

\footnotetext{
${ }^{21}$ This is an Intention to Treat design, as we do not actually observe fertility and mating behavior around the time, i.e., we cannot rule out that some women who were assigned treatment did not actually receive treatment.
} 
municipalities that experienced rationing, compared to municipalities that did not, thus supporting the common trends assumption inherent to this design.

\subsection{Long-term fertility and birth spacing}

In addition to the short-term effect, we make headway in the literature by tracing out the long-term fertility effect of a temporary shock. By studying the effect of a temporary shock on fertility 12 years after the power rationing ended, we can check if fertility is smoothed over time (Ward and Butz 1980; Barmby and Cigno 1990). In particular, the total number of children in the lifetime of a woman may not be affected by the power outage because increased fertility during the blackout might be compensated for with less fertility in later years.

In order to identify the long-run effect, we take a difference-in-difference approach. In the first difference, we consider women who gave birth 9 months after any blackout month and check if their number of children in 2005 differs between blackout and non-blackout areas. In the second difference, we repeat the same exercise but for women who gave birth in the first 9 months of the blackout. The timing of the birth for both sets of women is illustrated in Fig. 5. Women who gave birth in the first 9 months of the blackout are unlikely to conceive during the blackout because of post-natal care and post-partum amenorrhea. ${ }^{22}$ The first difference allows us to filter out any difference in fertility that is driven by both the blackout and other potentially confounding trends between blackout and non-blackout areas. The second difference allows us to filter out any difference in fertility that is not related to the blackout, since women who gave birth in the first 9 months of the blackout in both blackout and non-blackout areas did not actually experience the blackout during conception. In order to test our assumption of common trends, we present placebo checks whenever possible.

Formally, we estimate the following difference-in-difference equation:

$$
t c h_{m i c}=b_{m c}+\beta_{1} \times T_{i}+\beta_{2} \times T_{i} \times D_{m}+\epsilon_{m i c}
$$

where $t c h_{m i c}$ is the total number of children born to mother $i$ from age cohort $c$ in municipality $m$. The dummy $T_{i}$ equals zero if mother $i$ gave birth between March 1992 and November 1992, while it equals one if mother $i$ gave birth between December 1992 and December 1993. The dummy $D_{m}$ measures, as before, the power outage in 1992. Note that in this setup, we cannot control for mother-fixed effects, as there is only cross-sectional variation in the dependent variable. The coefficient of interest is $\beta_{2}$, which measures the change in long-run fertility of mothers who gave birth because of the blackout.

\footnotetext{
${ }^{22}$ As per the sample, only $6 \%$ of mothers gave birth in both the treatment and control periods. Since the treatment period covers more than a year, and the control period was for only nine months, it is possible for a mother to have given birth during both periods. The results are robust to the inclusion of these women in the estimating example and are available upon request. We exclude this subset of mothers from the analysis for ease of interpretation.
} 
The variable $b_{m c}$ is a set of municipality-age cohort fixed effects. They control for common shocks to women of the same year of birth cohort within a municipality. These fixed-effects help us take out any mother age-specific heterogeneity at the municipal level. Naturally, these fixed effects cannot control for the unobserved timevarying shocks that may have affected women during the period from 1993 to 2005. However, these shocks would only bias our estimated coefficients if they are correlated with the treatment-that is, if the shocks differentially affected women in the same age cohort and municipality whose only difference was that they could not physically conceive during the outage period, as either they had just delivered a baby or were already pregnant. Note that the level effect of the outage measure $D_{m}$ is captured by the municipality-birth year fixed effect $b_{m c}$.

We explore the time in between births-measured as the number of months between individual birth events - as a second margin of study. If the power outage led to an unanticipated increase in fertility of women, we would expect to see that the power outage reduced the time in between the blackout birth and the previous birth. Such an analysis is naturally only possible for the sample of women who had already given birth once. Similarly, we also explore the extent to which the time between birth changes for subsequent births. If women tried to offset an unexpected birth by having fewer children later, then one would expect there to be an increase in the time between the blackout birth and the posterior birth for mothers in blackout areas.

\subsection{Separating selection from long-run effects}

The third exercise consists of a study of the underlying patterns between motherlevel covariates measured in 2005 and the fertility shock of 1993. For this purpose, we compare women in blackout and non-blackout municipalities who gave birth in 1993 with women in blackout and non-blackout municipalities who gave birth in 1992. The estimating equation is the same as (2), except that we explore a range of socioeconomic variables on the left-hand side. In particular, we consider whether a mother did not finish secondary school; whether she is single or separated; whether she owns certain assets that serve as household wealth proxies; and whether she is active or inactive in the labor market. Lastly, we also study two outcome variables that are available for the children themselves. We assess whether children conceived as a consequence of the blackout had a different disability status in 2005 (by which time they were 12-13 years old) and whether they were differentially likely to be attending school in 2005.

For the mother-level socioeconomic outcomes, there are two competing interpretations about what our estimates capture. The first is that the fertility shock may have caused differential socioeconomic outcomes itself. For example, mothers may drop out of school due to unplanned pregnancies. To test for this, we study whether differential effects occur between older and younger women with respect to completion of secondary schooling (a pre-determined characteristic for older women during the time of the blackout). The second interpretation is that we simply identify (fixed) socioeconomic characteristics of women who are responsive to the treatment and thus, capture selection into treatment. We attempt to address this issue by showing in 
Table 1 Long-run sample balance table

\begin{tabular}{|c|c|c|c|c|c|}
\hline & \multicolumn{2}{|l|}{ Control } & \multicolumn{2}{|c|}{ Treatment } & \multirow{2}{*}{$\begin{array}{l}P \text { val } \\
\mathrm{p}\end{array}$} \\
\hline & Mean & $\mathrm{N}$ & Mean & $\mathrm{N}$ & \\
\hline Age in 2005 & 39.32 & 22347.00 & 38.40 & 40256.00 & $<0.01$ \\
\hline Power outage intensity & 0.26 & 22347.00 & 0.27 & 40256.00 & 0.29 \\
\hline Lights in 1992 & 6.79 & 22347.00 & 6.67 & 40256.00 & 0.13 \\
\hline Placebo outage intensity & -0.00 & 22280.00 & -0.01 & 40129.00 & 0.06 \\
\hline Births prior to 1992 & 1.56 & 22008.00 & 1.48 & 39766.00 & $<0.01$ \\
\hline Disabled? & 0.05 & 22347.00 & 0.05 & 40256.00 & 0.92 \\
\hline Literate? & 0.94 & 22347.00 & 0.94 & 40256.00 & 0.84 \\
\hline Ethnic minority & 0.13 & 22347.00 & 0.13 & 40256.00 & 0.13 \\
\hline Internal migrant? & 0.45 & 22347.00 & 0.46 & 40256.00 & 0.41 \\
\hline Any child died? & 0.08 & 22347.00 & 0.08 & 40256.00 & 0.56 \\
\hline Total number of children born & 2.79 & 22347.00 & 2.82 & 40256.00 & 0.06 \\
\hline Primary school completed & 0.75 & 22347.00 & 0.75 & 40256.00 & 0.62 \\
\hline Secondary school dropout & 0.42 & 12135.00 & 0.42 & 22121.00 & 0.82 \\
\hline Some University? & 0.22 & 7039.00 & 0.23 & 12801.00 & 0.40 \\
\hline Divorced/separated & 0.10 & 22195.00 & 0.10 & 39973.00 & 0.05 \\
\hline Single mother household & 0.15 & 22347.00 & 0.15 & 40256.00 & 0.37 \\
\hline Household assets & 1.98 & 21818.00 & 1.96 & 39581.00 & 0.03 \\
\hline Inactive in labor market & 0.59 & 22347.00 & 0.60 & 40256.00 & 0.22 \\
\hline
\end{tabular}

Source: This table presents the simple averages and the $p$ values of the difference in means of the variables between the treatment and control groups as defined in Fig. 5

Table 1 that women who gave birth in 1992 and 1993 did not differ systematically across a range of predetermined characteristics. ${ }^{23}$

\section{Results}

\subsection{Short-term fertility effect}

Our first results indicate that short-term fertility increased due to the period of extensive power rationing. The results are presented in Table 2 . The reported coefficients are multiplied by 100 for ease of exposition. The estimated coefficient on the interaction term between power outage intensity and treatment are positive and significantly

\footnotetext{
${ }^{23}$ An additional identification concern comes from the impact of the drought that led to the blackout on fertility and other outcomes. However, this concern would only be valid as long as the impact of the drought varied between blackout and non-blackout areas. Additionally, if the concern were true, then we would expect to see differential effects when studying the impact of the outage in rural versus urban areas, since the former are much more dependent on agricultural incomes. We do not, however, find a differential effect, as presented in Appendix Tables 14-18.
} 
Table 2 The impact of power outage intensity on birth probability

\begin{tabular}{|c|c|c|c|c|c|c|}
\hline \multirow{4}{*}{ Treated $\times$ power outage } & \multicolumn{6}{|c|}{ Different fixed effects } \\
\hline & (1) & (2) & (3) & (4) & (5) & (6) \\
\hline & $0.359 * * *$ & $0.365^{* * *}$ & $0.361 * * *$ & $0.361 * * *$ & $0.297 * * *$ & $0.289 * * *$ \\
\hline & $(0.086)$ & $(0.087)$ & $(0.088)$ & $(0.092)$ & $(0.099)$ & $(.099)$ \\
\hline Year FE & & Yes & Yes & Yes & & Yes \\
\hline Municipality FE & & & Yes & & & \\
\hline Mother FE & & & & Yes & Yes & Yes \\
\hline Region $\times$ year FE & & & & & Yes & \\
\hline Municipality trends & & & & & & Yes \\
\hline Mean birthrate & 0.0789 & 0.0789 & 0.0789 & 0.0789 & 0.0789 & 0.0789 \\
\hline Women & 457312 & 457312 & 457312 & 457312 & 457312 & 457312 \\
\hline Observations & 3658496 & 3658496 & 3658496 & 3658496 & 3658496 & 3658496 \\
\hline Clusters & 515 & 515 & 515 & 515 & 515 & 515 \\
\hline
\end{tabular}

Notes: Significance levels are indicated as $* 0.10$, **0.05, and *** 0.01. Standard errors (in parentheses) are clustered at the municipality level. The dependent variable is an indicator variable equal to one in case the mother experiences a birth in a given year. Power outage is a dummy variable equal to one if a municipality experienced above median power rationing in 1992. Treated is an indicator equal to one for the year 1993. The coefficients are multiplied by 100 for better exposition

different from zero. In column (2), we add year fixed effects; in column (3), we add municipality fixed effects; and in column (4), we replace municipality fixed effects by mother fixed effects. The coefficient remains very stable and does not change when adding the mother fixed effects, suggesting the treatment was indeed quasi random. In column (5), we replace the year effect by region-year fixed effect. Finally, we control for municipality-level linear trends in column (6). Even in the most demanding specification, our estimate remains stable and precisely estimated. According to our estimate in column (5), the 1992 blackout increased the probability of a woman giving birth in the next year by around 0.297 percentage points. Since the probability of giving birth in any given year is $7.8 \%$, the blackout boosts the probability of giving birth in 1993 by almost 4\%. Our estimates suggest that the number of children born due to the power-outage was between 6,608 and $8,346 .{ }^{24}$ Since roughly 360,000 babies were born on average every year, we estimate that between 1.8 and $2.3 \%$ of the babies born in 1993 were due to the power outage. The same figure for our preferred specification in column (5) is 6,791 of blackout-induced babies or $1.9 \%$ of the babies born in 1993.

We consider a few robustness checks to ensure the validity of our results in Table 3. For reference, column (1) presents the preferred specification from Table 2. Since the

\footnotetext{
${ }^{24} \mathrm{We}$ arrive at this figure by multiplying our lower and upper estimates of 0.289 and $0.365 \%$ by the total number of mothers in the sample, 457,312 . Next, we multiply this result by 0.5 to obtain the number of mothers who experienced a blackout above the median intensity. Next, we multiply by 10 , since the census micro-data pertains to only $10 \%$ of the population.
} 


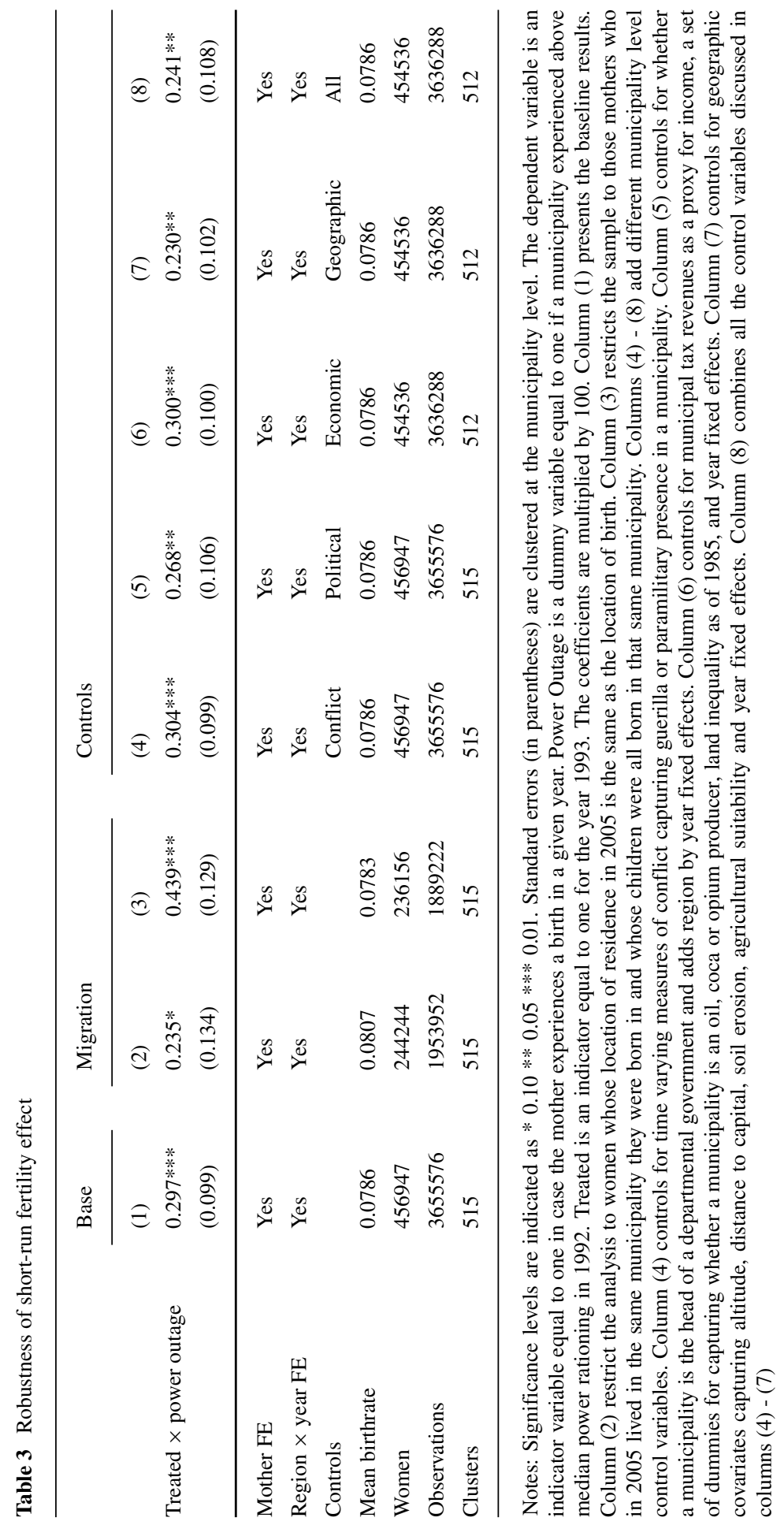


census sample was conducted in 2005 , a major concern with our results is that mothers may have moved across municipalities since 1993, causing us to falsely assign sets of women to the respective power outage treatment. If there is no systematic relationship between migration and the power outage in 1993, we would expect this to induce us to underestimate the effect due to attenuation bias. On the other hand, if the relocation choice of the mother is correlated with some unobserved characteristic of the municipality in 1993, we would have biased estimates for the effect of power outage on probability of birth. In order to address this, we restrict our sample in column (2) of Table 3 to women who were born in the same municipality where they lived in 2005 and hence have most likely lived there all their lives. In column (3), we restrict the sample to mothers who report having their last birth prior to 1993 in the same municipality they reported as their current residence. The sample shrinks considerably in both cases, rendering the estimates slightly less precise; however, the point estimate does not change much. Column (4) controls for time-varying measures of conflict, capturing guerrilla or paramilitary presence in a municipality. This is important, since the period saw significant turmoil with conflicts between the guerrilla and paramilitary groups and the central government. The results remain unaffected. Column (5) controls for whether a municipality is the head of a departmental government, interacted with region by year fixed effects. This flexibly controls for the extent to which more politically significant municipalities may have been affected by the power rationing differentially. Again, the results remain unaffected. Column (6) controls for municipal tax revenues as a proxy for income; a set of dummies for capturing whether a municipality is an oil, coca or opium producer; and land inequality as of 1985 , each interacted with year fixed effects. These economic covariates rule out some potentially time-varying shocks or trends, which may be proxied by our outage measure or may independently affect fertility. Since we exploit some spatial variation, in column (7), we control for geographic covariates capturing altitude, distance to capital, soil erosion, and agricultural suitability, each interacted with year fixed effects. Column (8) combines all the control variables discussed in columns (4)-(7). Reassuringly, our point estimate remains stable in all of these specifications. ${ }^{25}$

In order to test the common trend assumption inherent to our approach, we explore how our estimated coefficient varies when the blackout measure $D_{m}$ interacts with each year separately. The estimated coefficients and their respective confidence intervals are presented in Fig. 6. It can be observed that our outage measure is only statistically significant in 1993, the year immediately following the blackout. There is a weak, but insignificant uptick in fertility in 1992, which is not surprising since some of the babies conceived during the blackout were born in the last month of 1992. These results give us confidence that 1993 was indeed an exceptional year in terms of fertility due to the power rationing during $1992 .^{26}$

Next, we explore the mechanisms through which the blackout increased fertility by looking at heterogeneous effects by 5-year age groups. The coefficients and the confidence intervals for each group are presented in Fig. 7. The only statically

\footnotetext{
${ }^{25}$ Instead of using the dummy variable $D_{m}$ to measure the blackout, we could use the noisier continuous measure $O_{m}$. Using the continuous measure decreases the signal to noise ratio due to the aforementioned
} 


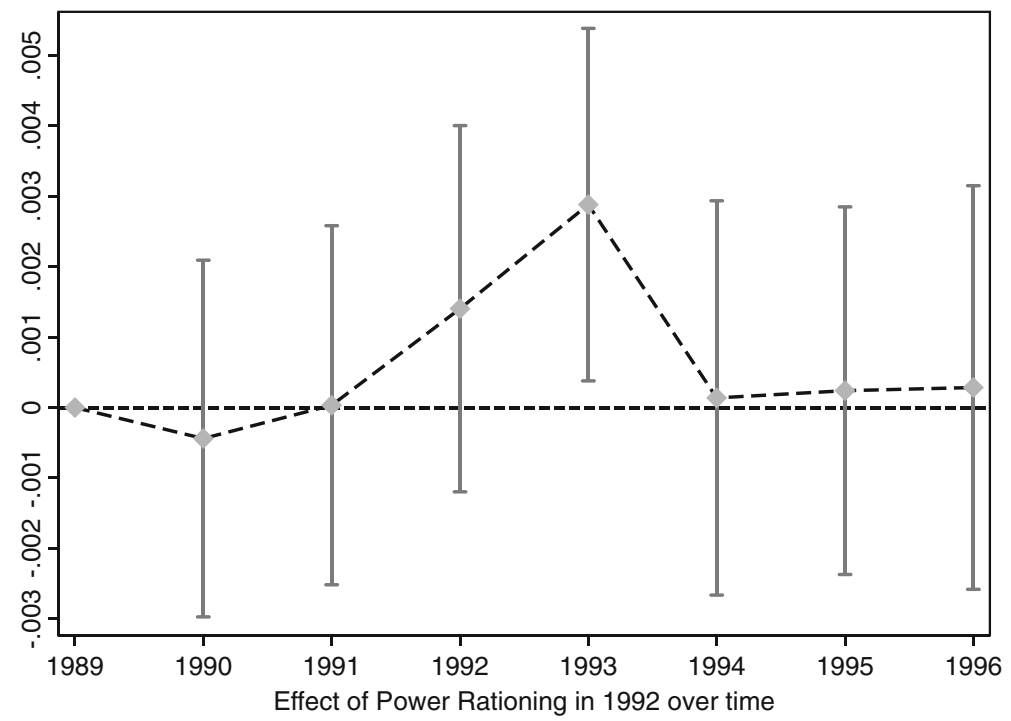

Fig. 6 This figure presents the effect of power rationing on the probability of a mother giving birth over time, conditioning on mother and region by year fixed effects. 95\% confidence intervals obtained from clustering standard errors at the municipality level are indicated

significant effects are for women between the ages of 17 and 21 and between 37 and 41. Therefore, the blackout has affected the fertility behavior of women either at the start or at the end of their reproductive age. This could suggest an important driver for the underlying fertility effect: the inattention to contraception of women who either have limited reproductive experience or assumed that they had already passed beyond their reproductive years. ${ }^{27}$

\subsection{Long-term fertility and birth spacing}

Having fewer children in the future may dynamically offset the temporary fertility increase found in the previous section. In panel A of Table 4, we show that this is

measurement error, resulting in attenuation bias and a slight loss of precision across a few specifications. The results obtained from the continuous measure, presented in Appendix Tables 10-13, are overall consistent with the ones obtained with the dummy measure.

${ }^{26}$ An alternative way to study this is by examining the effect of luminosity levels in 1992 on the probability that a mother gave birth in any given year between 1989 and 1996. We find no effect of luminosity on probability of birth other than for the year 1993. In this year, the probability of giving birth is significantly lower for municipalities that were relatively brighter in 1992. The regressions estimates are presented in Appendix Fig. 10.

${ }^{27}$ Our results are consistent with the underlying mechanisms suggested by Clarke et al. (2016), who look at seasonality of births. They show that the proportion of good season births follows a downward trajectory for women above the age of 32 . Their claim is that this is partly driven by younger women being better able to control the timing of their births and the inattention of older women. Their sample does not, however, include women younger than 20 , the other age group in which we find a significant effect. 


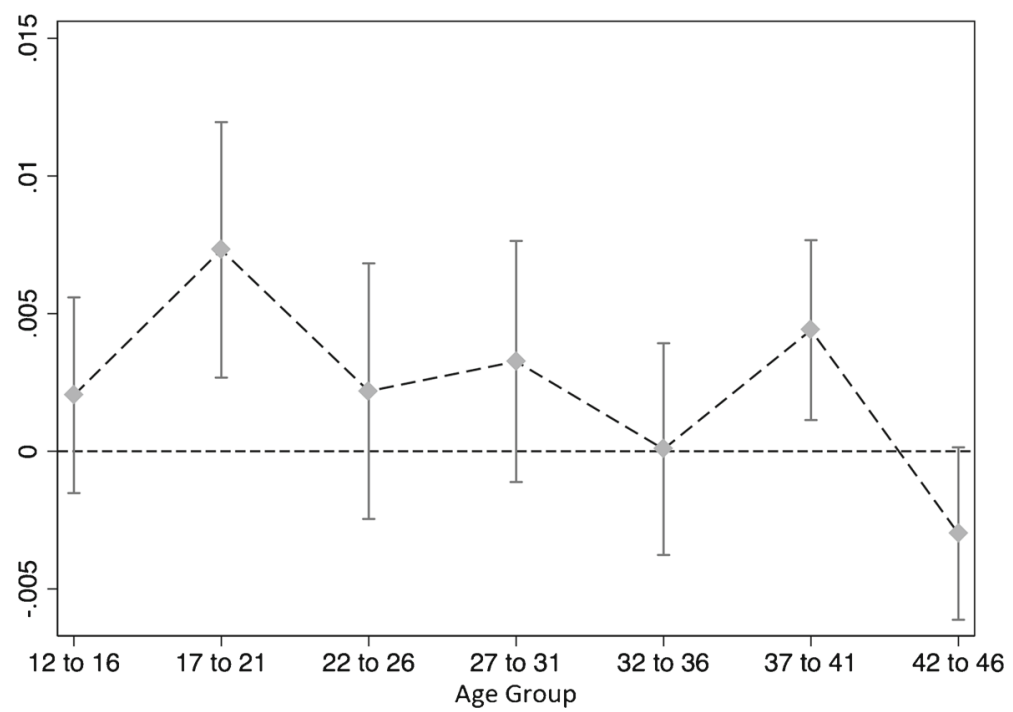

Fig. 7 This figure presents the effect of power rationing intensity on the probability of a mother giving birth in 1993 by mother's age group, controlling for mother and region by year fixed effects. 95\% confidence bands obtained from clustering at the municipality level are indicated. The positive fertility effect is driven by women between the ages of 17 and 21 and by women between the ages of 37 and 41

not the case. Column (1) is a simple difference-in-difference regression without any controls. The coefficient on the interaction term is positive and highly significant. This means that the mothers who gave birth in 1993 in a municipality affected by the power outage had more children overall compared to mothers who gave birth in the same municipality just prior to the outage. We subsequently add controls and higher level fixed effects in columns (2)-(5), and the result remains stable throughout. In particular, in column (4), we add municipality-birth year fixed effects to make sure that our effect is estimated solely off variation between mothers across the same age group.

Overall, our estimation suggests that -13 years later-women who conceived their babies under power-rationing conditions had, on average, 0.07 more children than women who conceived under different conditions. Based on this estimate, we can approximate the long-run fertility effect of the power outage on the aggregate of the population. The result is that by 2005, around 14,090 additional children had been born because of the blackout. ${ }^{28}$ Since the average age in our estimating sample in 2005 is just shy of 40, it is unlikely that the effect will be smoothed away as a large share of women have passed the reproductive period, suggesting a remaining overall increase in fertility.

\footnotetext{
${ }^{28} \mathrm{Half}$ the 40,256 women who conceived during the blackout period were living in blackout municipalities. $7 \%$ of this group of women had not yet offset the blackout-linked pregnancy by having fewer subsequent pregnancies in the ensuing 12 years. Again, we scale up by 10 because the micro-census data is a $10 \%$ sample.
} 
Table 4 Long-run fertility effect overall and by age group
(1)
(2)
(3)
(4)
(5)

Panel A: All women

\begin{tabular}{llllll} 
Treat $\times$ power outage & $\begin{array}{l}0.070 * * * \\
(0.026)\end{array}$ & $\begin{array}{l}0.070 * * * \\
(0.025)\end{array}$ & $\begin{array}{l}0.070 * * * \\
(0.025)\end{array}$ & $\begin{array}{l}0.068 * * * \\
(0.025)\end{array}$ & $\begin{array}{l}0.073 * * * \\
(0.028)\end{array}$ \\
\hline $\begin{array}{l}\text { Municipality FE } \\
\text { Birth year cohort FE }\end{array}$ & \multicolumn{2}{c}{ Yes } & Yes & & \\
Municipality $\times$ birth year FE & & & Yes & Yes & Yes \\
$\begin{array}{l}\text { Region } \times \text { treatment } \\
\text { Mean number of births post 1992 }\end{array}$ & 2.8 & 2.8 & & & Yes \\
Women & 62318 & 62318 & 62318 & 62318 & 62318 \\
Clusters & 515 & 515 & 515 & 515 & 515
\end{tabular}

Panel B: Women younger than 21

$\begin{array}{llllll}\text { Treat } \times \text { power outage } & 0.081^{*} & 0.092 * * & 0.093 * * & 0.089 * & 0.081 \\ & (0.049) & (0.045) & (0.045) & (0.050) & (0.054) \\ \text { Municipality FE } & & \text { Yes } & \text { Yes } & & \\ \begin{array}{l}\text { Birth year cohort FE } \\ \text { Municipality } \times \text { birth year FE }\end{array} & & \text { Yes } & & \text { Yes } & \text { Yes } \\ \begin{array}{l}\text { Region } \times \text { treatment } \\ \text { Mean number of births post 1992 }\end{array} & 2.78 & 2.78 & 2.78 & 2.78 & \text { Yes } \\ \text { Women } & 17862 & 17858 & 17858 & 17862 & 17862 \\ \text { Clusters } & 515 & 511 & 511 & 515 & 515\end{array}$

Panel C: Women older than 21

\begin{tabular}{llllll} 
Treat $\times$ power outage & $0.070 * *$ & $0.057 * *$ & $0.057 * *$ & $0.062 * *$ & $0.072 * *$ \\
& $(0.029)$ & $(0.027)$ & $(0.027)$ & $(0.029)$ & $(0.031)$ \\
$\begin{array}{l}\text { Municipality FE } \\
\text { Birth year cohort FE }\end{array}$ & & Yes & Yes & & \\
$\begin{array}{l}\text { Municipality } \times \text { birth year FE } \\
\text { Region } \times \text { treatment }\end{array}$ & & Yes & Yes & Yes \\
$\begin{array}{l}\text { Mean number of births post 1992 } \\
\text { Women }\end{array}$ & 2.81 & 2.81 & 2.81 & 2.81 & Yes \\
Clusters & 44456 & 44456 & 44456 & 44456 & 44456 \\
\hline
\end{tabular}

Notes: Significance levels are indicated as $* 0.10, * * 0.05$, and $* * * 0.01$. Standard errors (in parentheses) are clustered at the municipality level. Power outage is a dummy variable equal to one if a municipality experienced above median power rationing in 1992. Treated is an indicator equal to one for births occurring in the treatment time window as defined in Fig. 5. The dependent variable in panel A is the total number of births since 1990. The dependent variable in panel B is the time gap in months since the last birth, thus restricting the analysis to the set of mothers in the treatment and control groups who already had a child prior to treatment 
In panels $\mathrm{B}$ and $\mathrm{C}$ of Table 4, we focus on the long-run effect on fertility for women who were younger than 21 (panel B) and for women who were older than 21 (panel C). The point estimates are similar throughout, albeit slightly larger for younger women. We use finer age groups in Appendix Fig. 11. In this setup, the effect appears to be significant only for women who were between 17 and 21 years old at the time of the blackout. This induced us to pick the simpler specification where we compare the effect on women younger than 21 against the effect on women older than 21. Overall, there is evidence that at least younger women had not yet offset their increase in unexpected fertility by $2005 .^{29}$

By studying the length of time between births, we can provide further evidence of the differences between pregnancies that occurred during the power rationing and just prior to power rationing. Naturally, it is only possible to study the time in between births for the case of women who had already given birth once before. As a consequence, the sample size gets smaller. The results are presented in Table 5. From panel A, we see that, after controlling for fixed effects, the time between births decreases by 2 months as a consequence of the blackout. This result is consistent with our interpretation of the unexpected nature of the 1993 births in blackout areas. Panel B and panel $\mathrm{C}$ show the different birth spacing effects for women younger than 21 and older than 21 , respectively. We only find a significant effect for older women. However, we are still very skeptical about younger women not being surprised by their blackout pregnancies. Since they already had an early pregnancy, young women in this subsample are more likely to be mindful about pregnancies than the average young woman.

In Appendix Table 20, we explore the time that passes between pregnancies before and during the blackout and the next subsequent birth. We find no statistically significant change in the time to the next birth following the blackout, which is consistent with the lack of adjustment in increased lifetime fertility. ${ }^{30}$

\subsection{Selection versus socioeconomic consequences}

Bringing up a child is costly because it requires time spent away from working or obtaining a degree. In addition, women who have an unplanned child may find themselves in more unstable relationships. On the other hand, certain predetermined socioeconomic variables may render some women more responsive to underlying treatments such as power rationing. We shed light on these questions by checking the relation between the power outage and the socioeconomic outcomes of mothers measured 12 years after the blackout ended. The specification is the same as in (2).

\footnotetext{
${ }^{29} \mathrm{We}$ also check if the gender of the newborn child is of any consequence on any long-run effect, but find no evidence of this. The results can be provided upon request.

${ }^{30}$ In order to address migration concerns, we also check the effect on overall fertility and time between births for the subset of women who apparently did not migrate. These are women who not only lived in the same municipality that they were born in, but also reported that their children were born in that same municipality. The results, presented in Appendix Table 21, show that the point estimates are similar to the ones obtained using the overall sample, albeit estimated with slightly less precision.
} 
Table 5 Birth spacing: number of months passed since previous birth
(1)
(2)
(3)
(4)
(5)

Panel A: All women

$\begin{array}{cccccc}\text { Treat } \times \text { power outage } & -1.216 & -1.386^{*} & -1.742 * * & -1.852 * * & -2.141^{* *} \\ & (0.818) & (0.825) & (0.711) & (0.774) & (0.861)\end{array}$

Municipality FE

Birth year cohort FE

Municipality $\times$ birth year FE

Region $\times$ treatment

Average months between births

Women

Clusters

Panel B: Women younger than 21

Treat $\times$ power outage

Municipality FE

Birth year cohort FE

Municipality $\times$ birth year FE

Region $\times$ treatment

Average months between births

Women

Clusters

Panel C: Women older than 21

Treat $\times$ power outage

$\begin{array}{lllll}-1.448 & -1.416 & -1.884 * * & -2.067 * * & -2.369 * * \\ (0.927) & (0.933) & (0.807) & (0.873) & (0.963) \\ & \text { Yes } & \text { Yes } & & \\ & & \text { Yes } & & \\ & & & \text { Yes } & \text { Yes } \\ & & & & \text { Yes } \\ 51.5 & 51.5 & 51.5 & 51.5 & 51.5 \\ 27434 & 27433 & 27433 & 27434 & 27434 \\ 515 & 514 & 514 & 515 & 515\end{array}$

Notes: Significance levels are indicated as $* 0.10, * * 0.05$, and $* * * 0.01$. Standard errors (in parentheses) are clustered at the municipality level. Power outage is a dummy variable equal to one if a municipality experienced above median power rationing in 1992. Treated is an indicator equal to one for births occurring in the treatment time window as defined in Fig. 5. The dependent variable is the time gap in months since the last birth, thus restricting the analysis to the set of mothers in the treatment and control groups who already had a child prior to treatment. 
The results from this exercise are presented in panel A of Table 6. For reference, columns (1) and (2) present the main results for the total number of children born and the birth spacing that were presented in the previous tables. The remaining columns look at a range of socioeconomic characteristics measured 12 years after the end of the blackout period. Column (3) suggests that women who had a baby as a consequence of the blackout were 4.1 percentage points more likely to not have completed secondary school compared to women who got pregnant for other reasons (note that there are fewer observations as the results are conditional on the subsample of women who have finished primary school). Further socioeconomic measures are explored in columns (4)-(8). From columns (4) and (5), we see that women who had a blackout baby are more likely to be separated or single mothers. They are less likely to own assets like home appliances (column 6) and cars (column 7). Finally, they are more likely to be inactive in the labor market (column 8).

We explore child-level outcomes in columns (9) and (10). Children born to treatment and control mothers are aged between 12 and 14 years when the census information was collected. In column (9), we explore the extent to which children were classified as being disabled. We do not find any systematic evidence that children born to mothers who gave birth 9 months after the power outage are more likely to be disabled. Column (10) does not give any differential evidence with respect to school attendance either. Thus, we do not see any long run effects of the power outage on child-level outcomes.

In panels $\mathrm{B}$ and $\mathrm{C}$ of Table 6 , we present two different placebo exercises. To ensure there is no spurious relationship across time, in panel $\mathrm{B}$, we move the treatment and control groups 1 year earlier, comparing mothers who gave birth in 1991 and 1992. In panel C, to address concerns regarding the nighttime light measure capturing something different than the blackout, we construct a placebo measure of the blackout. We compare the nighttime lights of 1993 to those of 1994, 2 years without any reported disruption in electricity. The patterns suggest no systematic correlation structure, which is reassuring.

It is important to note that our estimates provide a local average effect driven by women responding to the treatment. It could thus be that women who respond to the treatment may be systematically different compared to their already pregnant sameaged peers who live in the same municipality, which we are wrongly interpreting as being a treatment effect. In order to address this concern, we study whether women in the treatment and control groups are systematically different across a range of predetermined socioeconomic characteristics. The results are presented in Table 7. Column (1) explores fertility prior to the outage, and the results suggest that women who responded to the treatment were not systematically different with regard to prior fertility compared to women in the control group. Naturally, we would expect that prior fertility might be strongly associated with the responsiveness to the treatment. It is thus reassuring, that there is no systematic difference in this regard. Similarly, women who responded to the treatment do not differ in terms of their ethnic minority status (ethnic minority status strongly correlates with poverty indicators), their literacy status, their primary school completion status, or their disability status. There is also no evidence suggesting that women were different in terms of their (internal) migration status or whether they ever had a child that died (this is only a cross-sectional characteristic). 


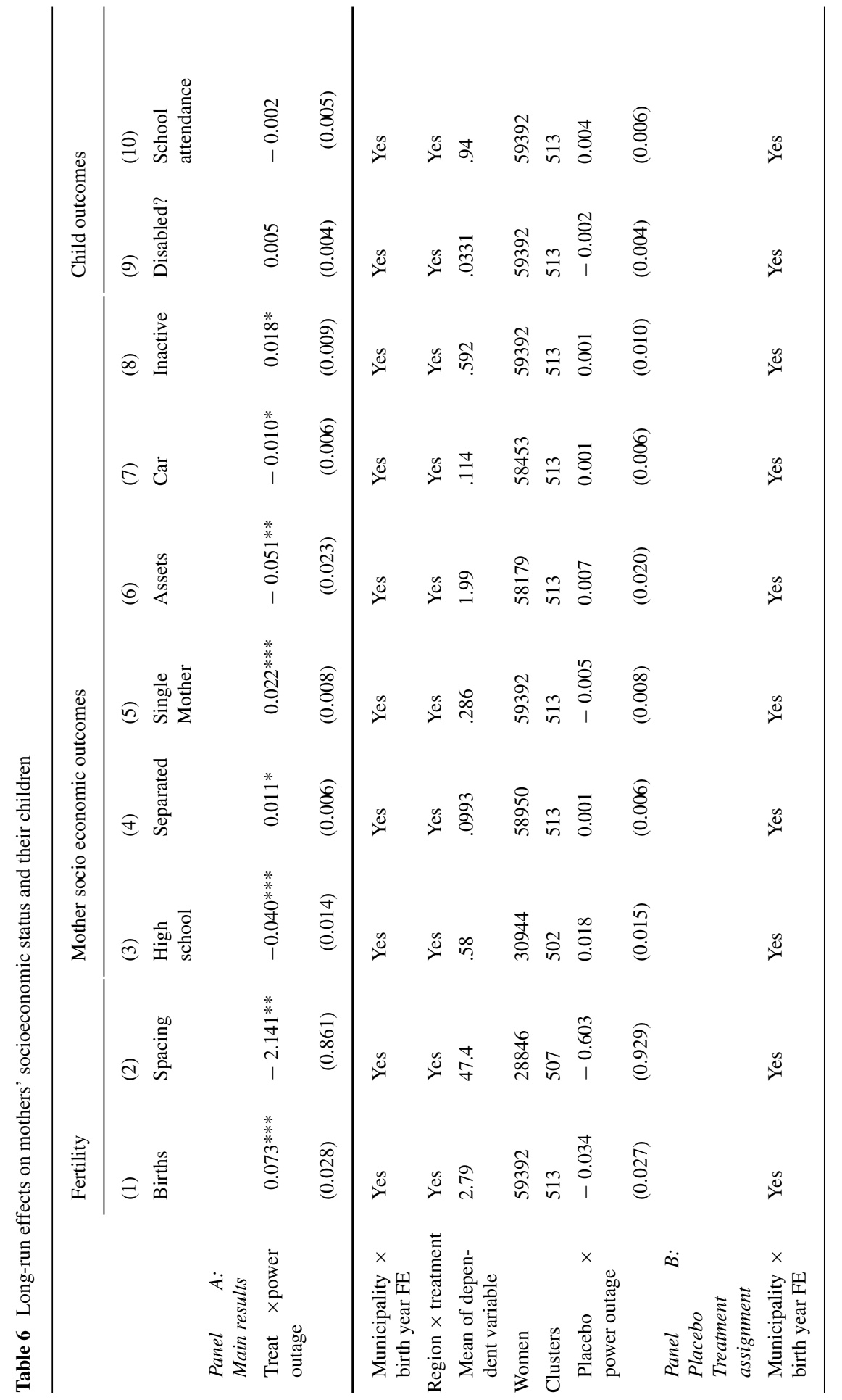




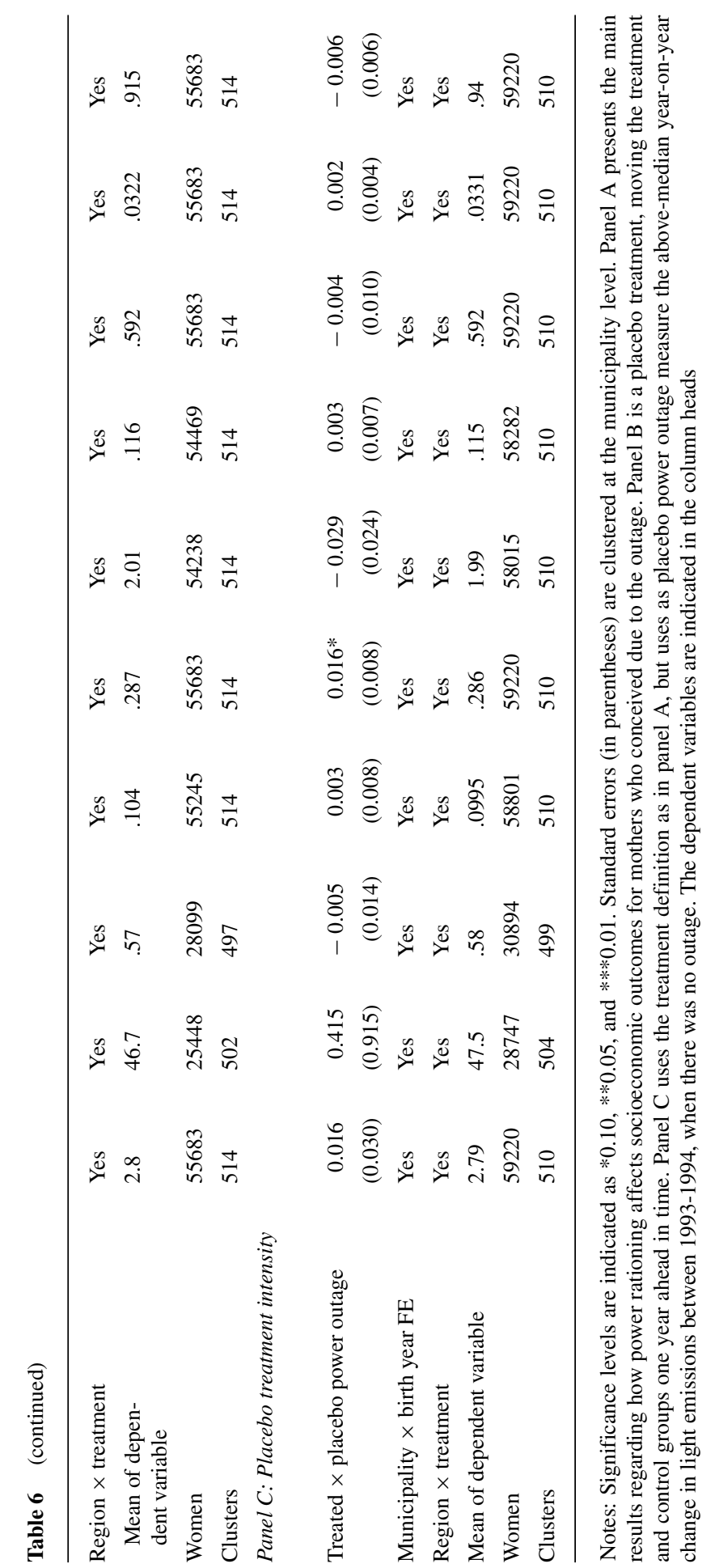




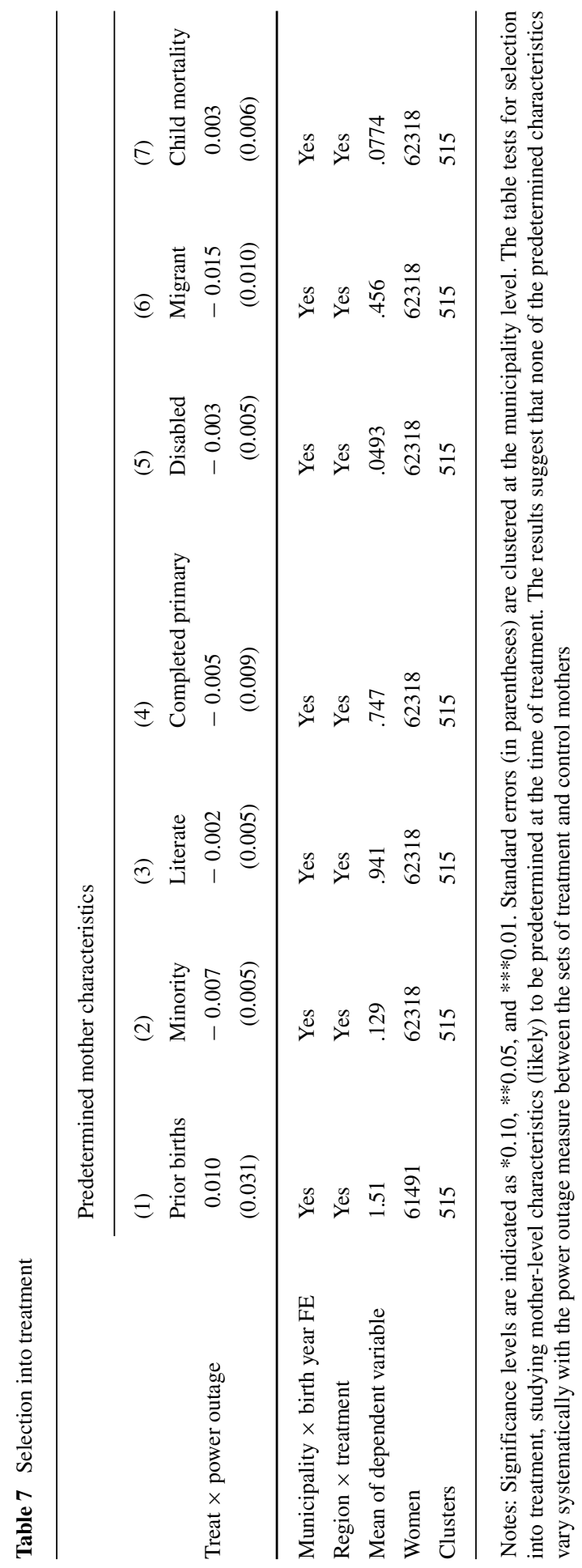


Especially for the variables in columns (1)-(5), we can be quite certain that these are predetermined characteristics. Overall, on a range of (likely) predetermined characteristics, women who gave birth in 1992 and women who gave birth in 1993 are very similar.

A second possibility to explore selection is by studying heterogeneous effects by age groups. Some socioeconomic characteristics (such as educational attainment) are more likely to be predetermined for older women as opposed to younger women. Any effect estimated for older women could be indicative of selection into treatment or capture inherent differences correlated in the responsiveness to the treatment. The results from this exercise are presented in Table 8. Panel A presents the overall results again, whereas panel $\mathrm{B}$ estimates - in addition to the main effect-a heterogeneous effect for women over the age of 21 at the time of treatment. Columns (1) and (2) present the results pertaining to overall fertility and birth spacing, confirming relatively homogenous effects across the two age groups. For the mother level socioeconomic outcomes across columns (3) to (8), we do not have sufficient statistical power to make a case that the estimated effects are different for younger women than they are for older ones. Of these, secondary schooling in column (3) is one variable likely to be pre-determined across the two age groups. We again fail to pick up any differences in high school outcomes for younger women when compared to older women. While we cannot rule out that our socioeconomic results capture unobservable characteristics that are correlated with the mother specific responsiveness to a treatment, we think that the evidence on pre-determined socioeconomic characteristics presented in Table 7 supports genuine treatment effects.

Lastly, columns (9) and (10) of panel B in Table 8 present the results of child-level outcomes differentiating between younger and older women. Column (9) suggests that pregnancies among young mothers who gave birth immediately after the power outage were more likely to result in a child being disabled, compared to pregnancies among young mothers whose children were conceived before the blackout. The observation of worse child health, as indicated by the self-reported disability status, is consistent with the medical literature suggesting that pregnancies among young women are commonly associated with health problems and disabilities for children. This is due to preterm birth, low birth weight, and asphyxia (Chen et al. 2007; WHO 2010). Unfortunately, at this stage, the census data does not allow us to distinguish between types of disabilities due to lack of information and the apparent limits on statistical power. ${ }^{31}$ Lastly, column (10) suggests that school attendance may be weakly lower for children born to young mothers. This is further indicative of the indirect social costs arising from the power rationing period. ${ }^{32}$

\footnotetext{
${ }^{31}$ Going forward, it will be interesting to explore these effects using data from the 2015 census. The micro data for that census is yet to be released.

${ }^{32}$ This last result has to be interpreted with caution. Given the strong evidence established in the literature regarding the intergenerational transmission of human capital (see Black et al. 2005), one can not rule out the possibility that the difference in childrens' schooling outcomes is due to the fact that the women who are responsive to the treatment are precisely the ones who are less educated.
} 


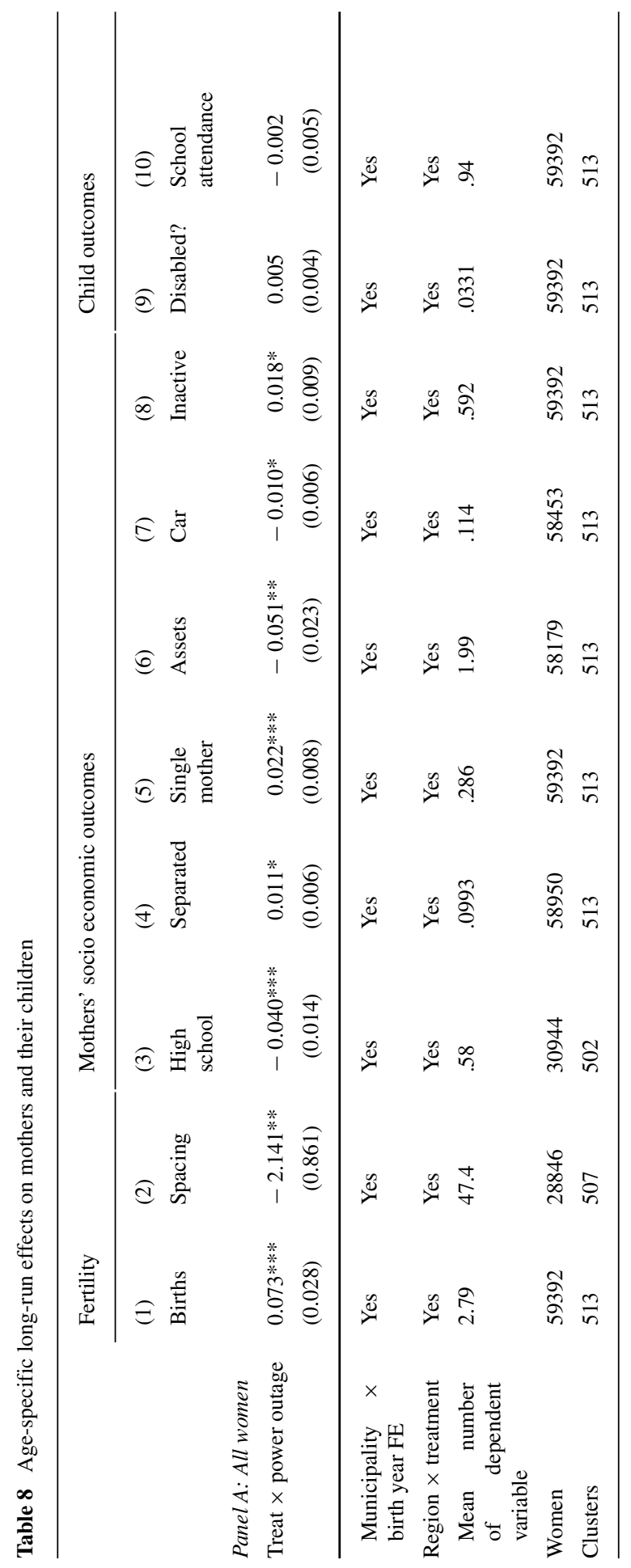




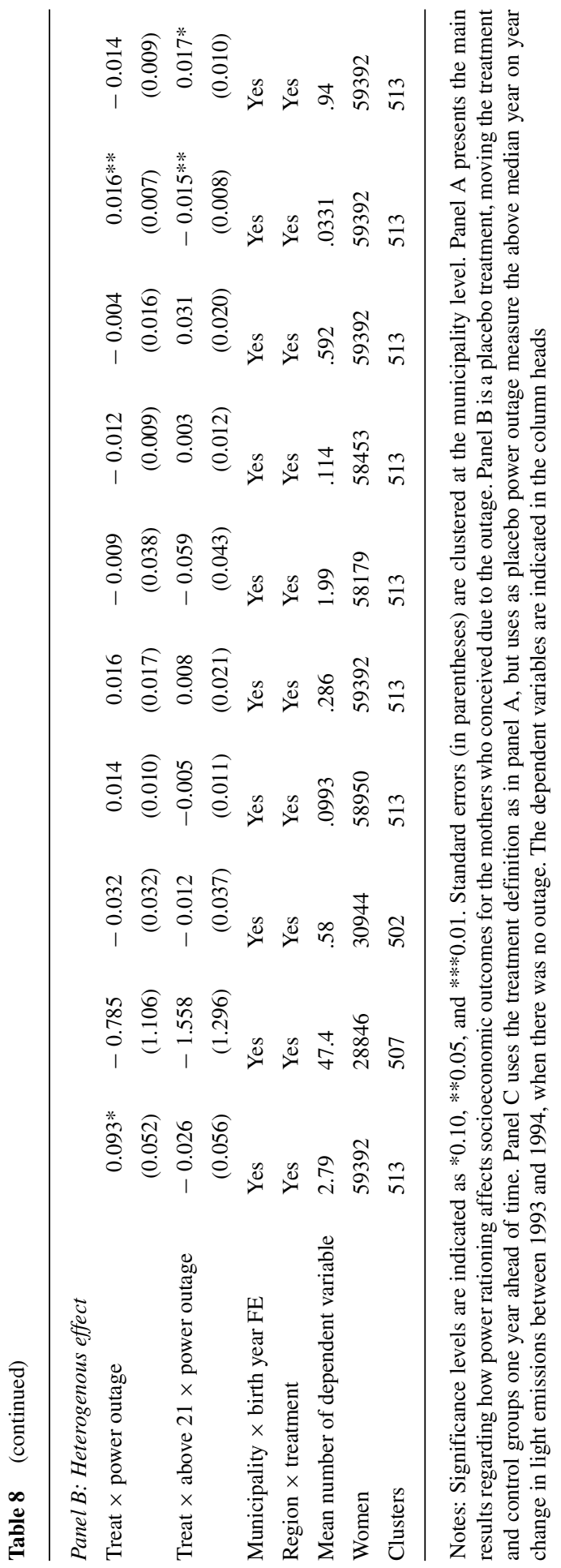




\section{Conclusion}

This paper set out to analyze the impact of power rationing in Colombia in the early 1990 s on fertility. In particular, it is the first attempt to evaluate the impact of power rationing on population dynamics, going beyond the question of whether power outages may cause "mini baby booms".

We exploit within-mother level variation to document a mini baby boom following a period of extensive power rationing in Colombia. We take this further by looking at fertility dynamics over time, finding that women who had a baby as a consequence of the blackout did not balance out their overall fertility in the 12 years that followed. Consistent with our interpretation that births due to the outage were likely to be unplanned, we show that the time between births is significantly reduced. Lastly, we document some evidence suggesting that women may have experienced worse socioeconomic outcomes as a result of the unplanned baby. While there appears to be limited concerns about selection into treatment, we cannot rule out entirely the possibility that the results are driven by selection. Nevertheless, the patterns we document are consistent with the existence of genuine treatment effects. All in all, our results suggest that fertility behavior seems to be quite responsive to unexpected infrastructure failures, indicating the existence of indirect social costs.

Acknowledgments We would like to thank the two anonymous reviewers for their suggestions and comments, as well as Sonia Balhotra, Tim Besley, Gharad Bryan, Alfredo Burlando, Jon de Quidt, Leonardo Felli, Jose Guerra, Samuel Marden, Luis Martinez, Gerard Padro i Miquel, Peter Postl, Juan Vargas, Guo $\mathrm{Xu}$ and seminar audiences at LSE, University of East Anglia, Warwick, NEUDC and CEP for helpful comments. The first author is the corresponding author and is based at University of Warwick, the second is based at Pontificia Universidad Javeriana - Facultad de Ciencias Econó micas, the third author is in Tanzania working in private sector development.

\section{Compliance with Ethical Standards}

Conflict of interest The authors declare that they have no conflict of interest.

Open Access This article is distributed under the terms of the Creative Commons Attribution 4.0 International License (http://creativecommons.org/licenses/by/4.0/), which permits unrestricted use, distribution, and reproduction in any medium, provided you give appropriate credit to the original author(s) and the source, provide a link to the Creative Commons license, and indicate if changes were made.

\section{A Online Appendix}

The online appendix for "More than an urban legend: the short and long-run effects of unplanned fertility shocks" provides additional information on the construction of variables and data sets, as well as further results and figures (Figs. 12, 13, 14 and 15).

\section{A.1 Nighttime Lights Power Outage Measures}

We construct a measure of power rationing from outer space, using satellite recorded nighttime light emissions. We use night light emission data collected from the United 
States Air Force Defense Meteorological Satellite Program (DMSP). These satellites carry an Operational Linescan System (OLS) sensor, which can be used to detect natural light emissions from earth. The primary aim of the sensors is to observe low intensity light emissions stemming from lunar light reflectance. The satellites were not designed to map human light emissions, yet the processed stable lights imagery has been shown to correlate extremely well with measures of economic development, incomes, electrification rates and urbanization (see Michalopoulos and Papaioannou 2013; Henderson et al. 2012; Jiang et al. 2014; Deichmann et al. 2014). Nighttime light data is appealing because it provides consistent data over a long time period on human activity in contexts where primary data is not widely available. While the satellites have been carrying the OLS sensors since the 1970s, a digital archive of the pictures is only available from 1992 onwards. The DMSP satellites orbit earth 14 times per day. This ensures that for each location on the globe there exists a daily picture taken between 8:30 and 10:00 pm local time. The satellites are regularly replaced every 3 to 4 years; sensors of older satellite deteriorate, which makes it challenging to compare images from new with that of old ones. Throughout, we use the images from the F12 satellite, providing data for the years 1992-1994.

Throughout the paper, we worked with the stable lights layer provided by the Earth Observatory Group at the National Oceanic and Atmospheric Administration. This layer is the cleanest in providing stable light emissions. In particular, forest fires and gas flares, systematic distortions due to the varying lunar intensity and late sunsets during summer or winter for the northern and southern hemispheres are removed from the stable lights layer. The result is supposed to capture light emissions from human settlements; this is measured on a digital scale between 0 and 63 , where 0 stands for no light emissions and 63 is the maximal value, which is top-coded. The pixel resolution is 30 arc-seconds or about 0.86 square kilometers at the equator.

Since the nighttime light data series is only available from 1992 onward, we can not compare the light intensity in the year 1992 (the year with the most extensive rationing) with previous years. Nevertheless, we can measure the changes between the years 1992 and 1993, comparing this change to subsequent years. If 1992 was a year with very low nighttime light emissions, then the year-on-year change between 1992 and 1993 is a good proxy for the extent of rationing.

Hence, we construct a simple measure that, with several refinements is computed using the following formula:

$$
O_{m}=100 \times\left(1-\frac{\text { Light }_{1992}}{\text { Lights }_{1993}}\right)
$$

To illustrate, if a pixel was unlit in 1992 and lit with any positive value in 1993, this measure would have a value of $100 \%$, capturing the observed lack of light emissions. Alternatively, if the pixel was lit with the digital number 10 in 1992, while it was lit with the digital number of 20 in 1993, the measure would have a value of 50\%, capturing the fact that a pixel emitted only half the amount of light. A look at aggregate figures is indicative of the extent of power rationing across Colombia in 1992.

For the main measure, we weight the data by initial 1990 municipality level population. The weighting by population becomes necessary as the IPUMS data merges 
several municipalities that have population sizes less than 20,000 to ensure that users of the data are not able to reverse-engineer who the individuals in the sample were. In total we are left with 515 municipalities that have population above 20,000 .

Unfortunately, the nighttime light data is suffering from measurement error. This measurement error has multiple sources.

1. Satellite images are not taken at the same point in time every night, but only in roughly the same time window in the evening. Clearly, dawn hours may have different light emission patterns compared to later in the evening.

2. Images are taken at different angles depending on the position of the satellite to the earth, which results in different over-glow patterns.

3. While ephermeral lights are supposed to be removed, there is still a chance that non-stable light sources (like fires or gas flaring) contaminate the images.

4. Cloud cover distorts or renders images useless, resulting in few data points for some locations.

Due to significant noise in the year-on-year changes in light emissions, we use a dummified outage measure throughout the paper. This measure captures whether power rationing is above median across the estimating sample. The median power rationing is around $18 \%$.

\section{A.2 Census Data and Birth History}

This section describes how we construct the data set used in the main body of the paper. Throughout, we work with the IPUMS public use census file from the General Census 2005 (XVII of Population and Dwelling and VI of Housing), collected by the Departamento Administrativo Nacional de Estadística (DANE). The sample population was the entire population of the country, including all households and dwellings. The data was collected between May 2005 and February 2006, with interruptions for vacation periods between June and July 2005 and between December 2005 and January 2006. IPUMS provides a micro-data sample covering approximately $10 \%$ of the overall population. The respondents in the survey were habitual residents over the age of 12. In the case of a person not being present or able to be interviewed, the information was provided by the head of household (male or female), his/her spouse or a resident over the age of 15 .

The geographic resolution is a municipality with a population of 20,000+. Smaller municipalities were merged with larger ones for confidentiality protection. A household is defined as a person or group of people, related or not, who occupy all or part of a dwelling, attend to basic needs charged to a common budget and generally share food.

For each household member inside a dwelling, the data contains a list of household members. Children living in the household in 2005 are linked to their parents, in case their parents are part of the household. This allows us to reconstruct the birth histories of mothers who still lived with their children. We can not distinguish 
between biological or non-biological parents. The relationships within a household are defined by the relationship to the head of the household, which, technically, could be any individual.

The whole dataset contains information on 2,327,228 individuals living in urban areas. The following sequence of steps describes how we arrived at our mother-level panel data set. ${ }^{33}$

1. First, we created a set of 457,312 women born between 1948 and 1978. These are women between 15 and 45 years old in 1993, when the bulk of children conceived in 1992 would be born. Each woman is identified by a household identifier as well as a person number within the household. In the same way, partners within a household are linked to one another, through their person number within the household. Lastly, each child is linked to its mother within a household through the person identifier of the mother.

2. In the second step, we mapped each potential mother to their cohabiting partner or spouse, in case one is present in a household. For the 469,855 potential mothers, 277,973 are linked to a partner within a household. The unmatched set of 191,882 women contains 58,434 single mother households (who have no partner in 2005) and 82,030 extended families.

3. In the third step, we merged the full remainder census dataset of $1,579,400$ individuals to the set of 457,312 potential mothers to obtain matches between mothers and children. This results in 745,691 children being matched to 346,507 birth mothers. We can use this to compare the extent to which we are able to map out a mothers' entire birth history. The raw data provides the total number of children every mother has ever given birth to up to the census date. We can compare this number to the number of children that still live in their mother's household in 2005 . For $55.7 \%(275,188)$ of the 346,507 matched birth mothers, we have reconstructed their entire birth history. Naturally, women with a birth history that we could not reconstruct are, on average, older.

4. In the fourth step, we compute the number of months since the most recent previous birth for every birth in our sample. This measure is bound to be noisy as it is only precise for women where we observed their entire birth history (i.e., women who in 2005 still live with all their children in the same household).

5. Using the set of 457,312 candidate mothers, we construct a balanced motherlevel panel covering the period from 1989 to 1996. This time frame is chosen since children born in 1989 were between 16-17 years old in the 2005 census. Since 18 years old is a common age at which children leave their households, this sample time frame ensures that our reconstructed birth histories are, most likely, the complete birth history for that sample time period.

The resulting dataset is a balanced panel with 3,658,496 observations.

\footnotetext{
${ }^{33}$ For more detailed information about the census, see https://international.ipums.org/international/ sample_designs/sample_designs_co.shtml.
} 


\section{A.3 Appendix Figures}

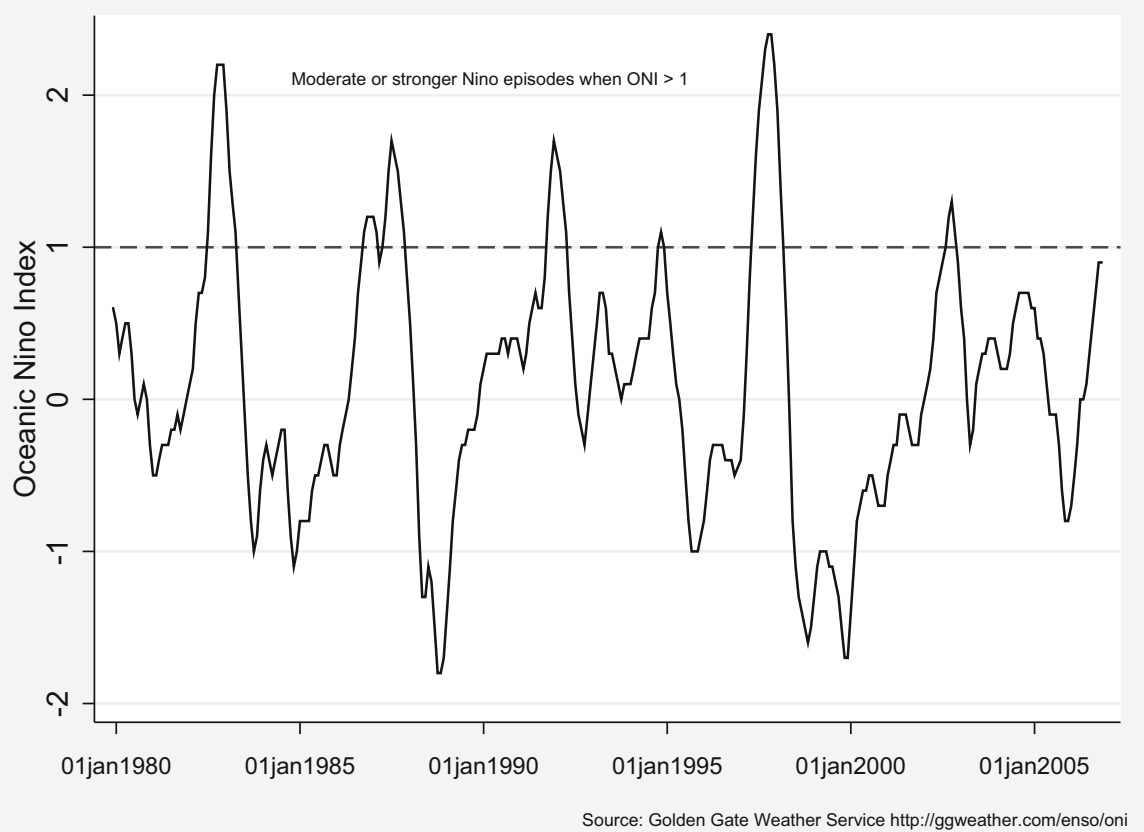

Fig. 8 Oceanic Niño Index

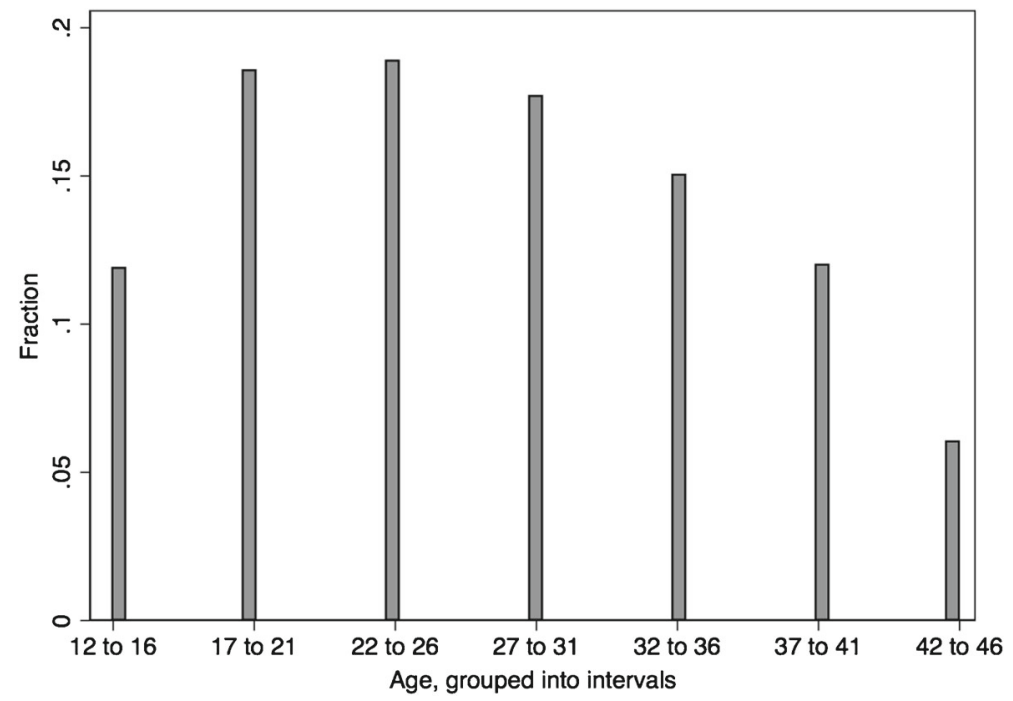

Fig. 9 Distribution of age of women in short-run estimating sample in 1992 


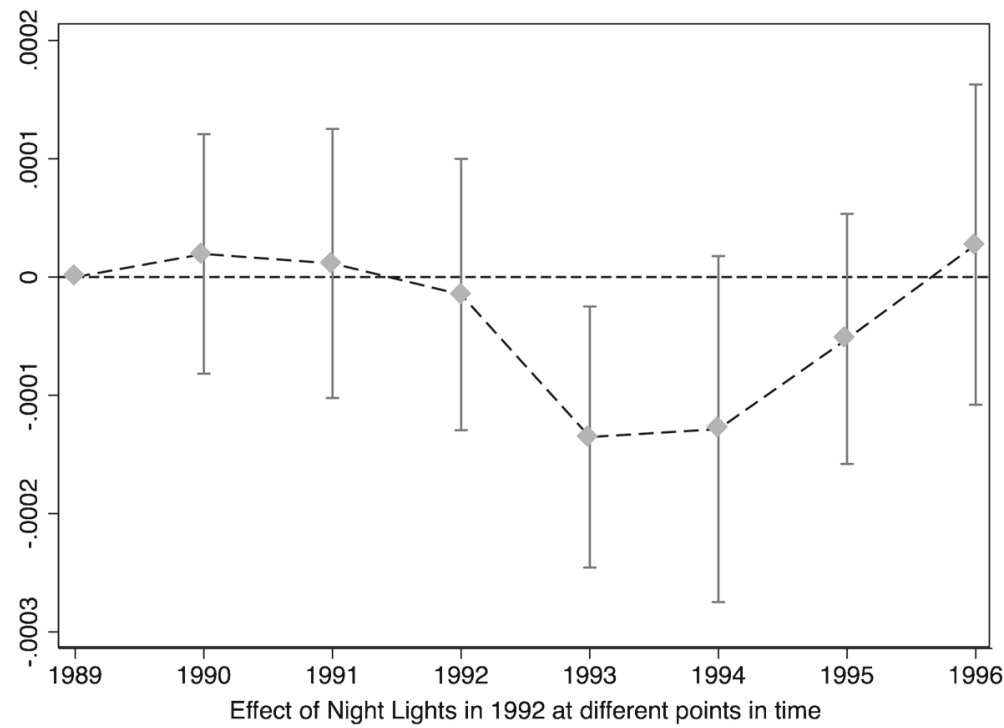

Fig. 10 This figure presents results from a regression studying the effect of nighttime light emissions in 1992 on the probability of a mother giving birth in a given year between 1989 and 1996, controlling for mother and region by year fixed effects. The results indicate that 1993 saw a drop in fertility rates in places that were relatively more lit in 1992, compared to places that were unlit

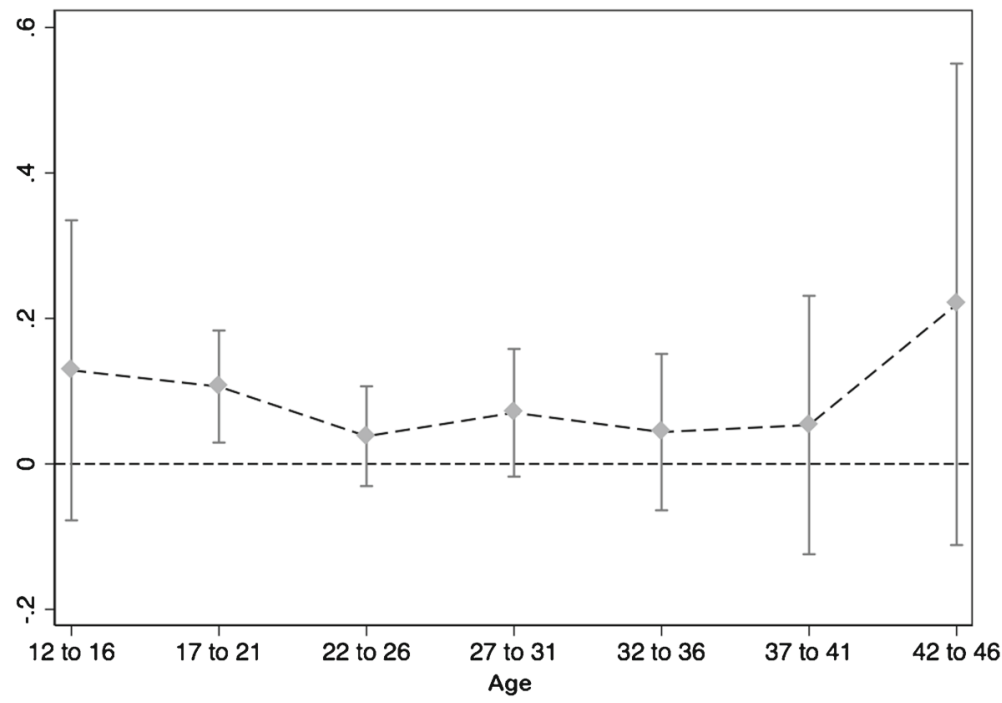

Fig. 11 This figure presents results from an age-heterogeneity exercise on the long-run fertility effect, while controlling for municipality and birth year cohort fixed effects. 95\% confidence bands obtained from clustering at the municipality level are indicated 


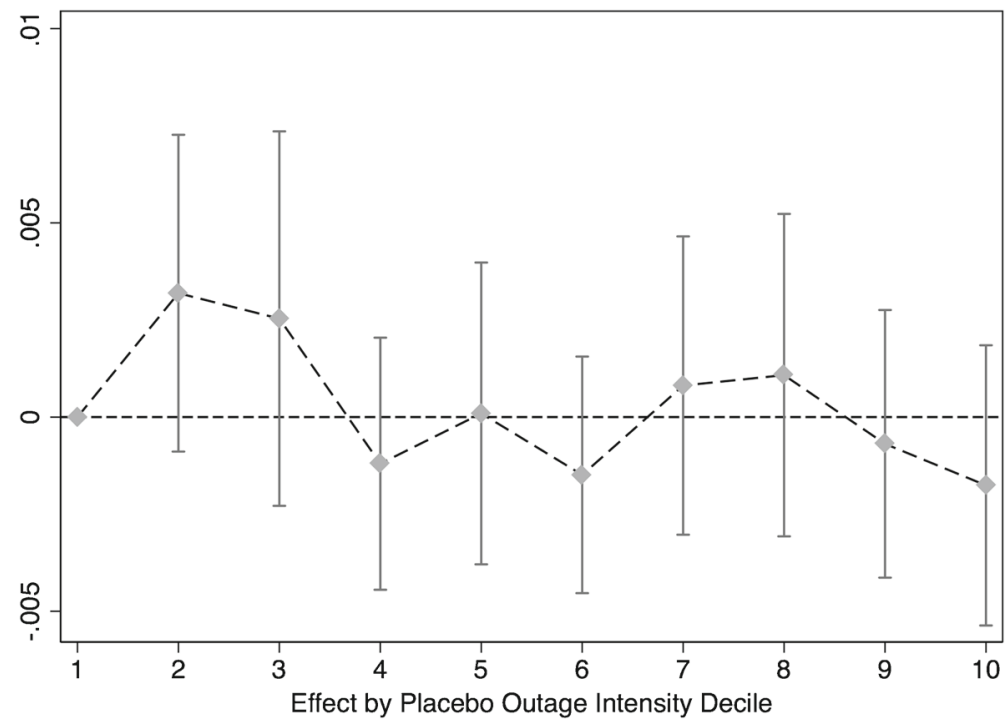

Fig. 12 This figure presents the effect of the placebo power rationing intensity by decile on the probability of a mother giving birth in 1993, while controlling for mother and year fixed effects. The effect is driven by municipalities with power rationing above median. $95 \%$ confidence bands obtained from clustering at the municipality level are indicated
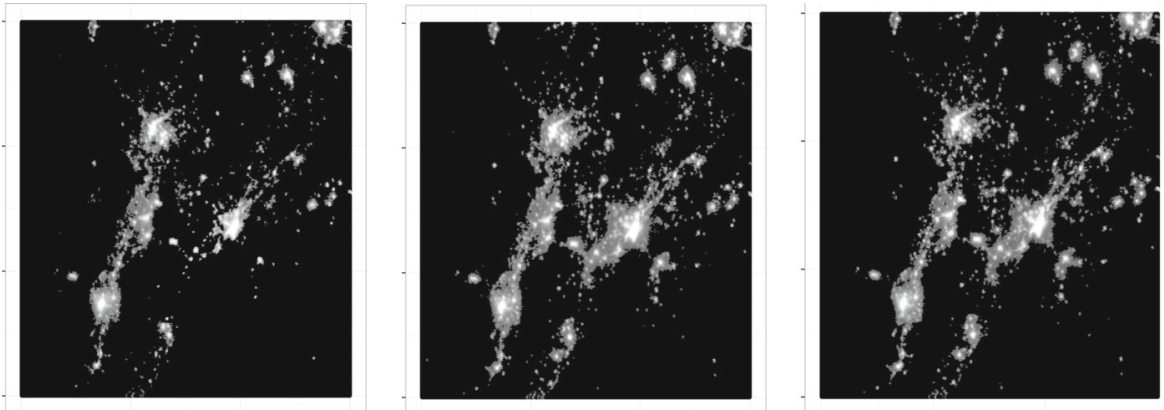

Fig. 13 Light intensity in Central Colombia, 1992 (left), 1993 (center) and 1994 (right) 


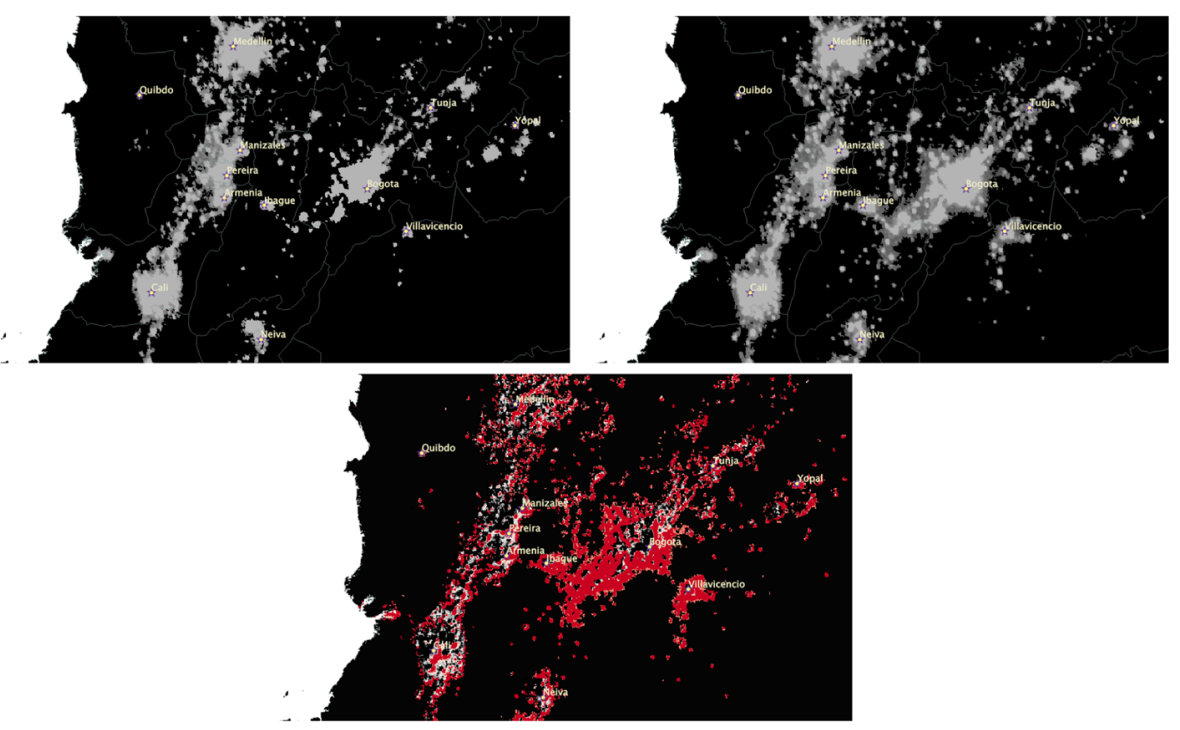

Fig. 14 The images above display the light intensity around Bogota in 1992 (left) versus light intensity around Bogotá in 1993 (right). The image in the center displays pixels that went from having some light in 1992 to no light in 1993 (i.e., completely dark). This is marked by the color red

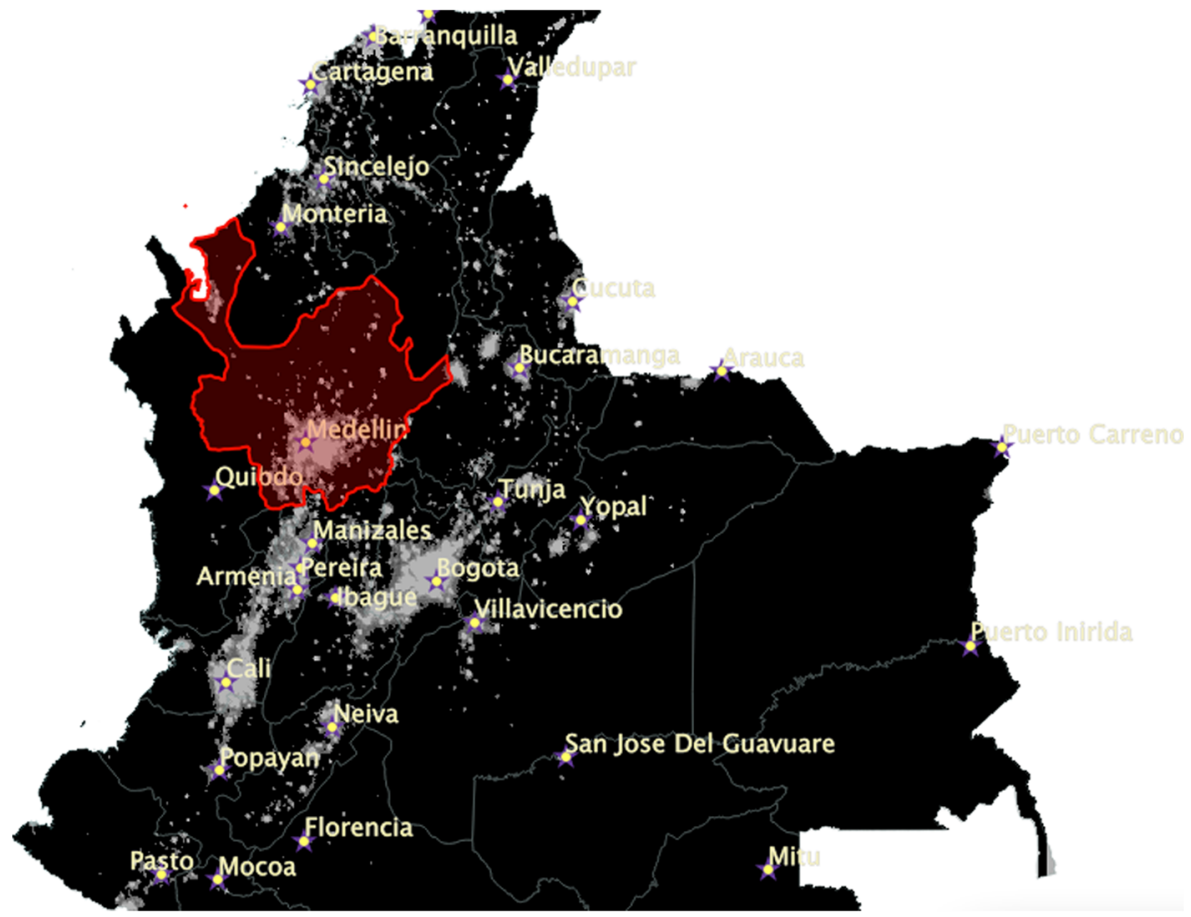

Fig. 15 Colombia Administrative Regions, Nighttime Light Emissions in 1992 and Provincial Capital Cities. The Antioquia department, where around $25 \%$ of the hydro electric power generation capacity is located, is highlighted 


\section{A.4 Appendix Tables}

Table 9 Summary of key events

\begin{tabular}{|c|c|}
\hline Date & Event \\
\hline Jan 92 & $\begin{array}{l}\text { The Oceanic Niño Index peaks. } \\
\text { Water sources for hydroelectric power depleting. }\end{array}$ \\
\hline 28th Feb 92 & Power rationing is announced. \\
\hline 2nd Mar 92 & Power rationing starts. \\
\hline Apr 92 & $\begin{array}{l}\text { The government starts to implement reforms to } \\
\text { stabilize long-run electricity supply. }\end{array}$ \\
\hline 1st Apr 93 & Power rationing ends. \\
\hline Oct 97 & $\begin{array}{l}\text { El Niño returns, but this time there is no need for } \\
\text { power rationing. }\end{array}$ \\
\hline
\end{tabular}

Table 10 Continuous power outage measure: impact of power outage intensity on birth probability

\begin{tabular}{|c|c|c|c|c|c|c|}
\hline \multirow{4}{*}{$\begin{array}{l}\text { Treated } \times \text { power } \\
\text { outage intensity }\end{array}$} & \multicolumn{6}{|c|}{ Different fixed effects } \\
\hline & (1) & (2) & (3) & (4) & (5) & (6) \\
\hline & $0.586^{* * *}$ & $0.585 * * *$ & $0.585^{* * *} *$ & $0.586 * * *$ & $0.468 * *$ & $.448 * *$ \\
\hline & $(0.172)$ & $(0.173)$ & $(0.171)$ & $(0.174)$ & $(0.197)$ & $(0.196)$ \\
\hline Year FE & & Yes & Yes & Yes & & Yes \\
\hline Municipality FE & & & Yes & & & \\
\hline Mother FE & & & & Yes & Yes & Yes \\
\hline Region $\times$ year FE & & & & & Yes & \\
\hline Municipality trends & & & & & & Yes \\
\hline Mean birthrate & .0789 & .0789 & .0789 & .0789 & .0789 & .0789 \\
\hline Women & 457312 & 457312 & 457312 & 457312 & 457312 & 457312 \\
\hline Observations & 3658496 & 3658496 & 3658496 & 3658496 & 3658496 & 3658496 \\
\hline Clusters & 515 & 515 & 515 & 515 & 515 & 515 \\
\hline
\end{tabular}

Notes: Significance levels are indicated as *0.10,**0.05, and ***0.01. Standard errors (in parentheses) are clustered at the municipality level. Outage $\times$ intensity measures the proportional change in municipalitylevel luminosity between 1992 and 1993. The dependent variable is an indicator variable equal to one, in case the mother experiences a birth in a given year. Note that the municipality fixed effects are perfectly collinear with the mother fixed effects in specifications (4)-(6). The coefficients are multiplied by 100 
Table 11 Continuous outage measure: long run fertility effect overall and by age group
(1)
(2)
(3)
(4)
(5)

Panel A: All women

\begin{tabular}{|c|c|c|c|c|c|}
\hline Treat $\times$ power outage intensity & $\begin{array}{l}0.138 * * \\
(0.054)\end{array}$ & $\begin{array}{l}0.136 * * * \\
(0.051)\end{array}$ & $\begin{array}{l}0.137 * * * \\
(0.051)\end{array}$ & $\begin{array}{l}0.120 * * \\
(0.050)\end{array}$ & $\begin{array}{l}0.140 * * \\
(0.056)\end{array}$ \\
\hline Municipality FE & & Yes & Yes & & \\
\hline Birth year cohort FE & & & Yes & & \\
\hline Municipality $\times$ birth year FE & & & & Yes & Yes \\
\hline Region $\times$ treatment & & & & & Yes \\
\hline Mean number of births & 2.8 & 2.8 & 2.8 & 2.8 & 2.8 \\
\hline Women & 62318 & 62318 & 62318 & 62318 & 62318 \\
\hline Clusters & 515 & 515 & 515 & 515 & 515 \\
\hline \multicolumn{6}{|l|}{ Panel B: Women younger than 21} \\
\hline Treat $\times$ power outage intensity & $\begin{array}{l}0.169 * \\
(0.093)\end{array}$ & $\begin{array}{l}0.178 * * \\
(0.088)\end{array}$ & $\begin{array}{l}0.181 * * \\
(0.088)\end{array}$ & $\begin{array}{l}0.155 \\
(0.099)\end{array}$ & $\begin{array}{l}0.148 \\
(0.113)\end{array}$ \\
\hline Municipality FE & & Yes & Yes & & \\
\hline Birth year cohort FE & & & Yes & & \\
\hline Municipality $\times$ birth year FE & & & & Yes & Yes \\
\hline Region $\times$ treatment & & & & & Yes \\
\hline Mean number of births & 2.78 & 2.78 & 2.78 & 2.78 & 2.78 \\
\hline Women & 17862 & 17858 & 17858 & 17862 & 17862 \\
\hline Clusters & 515 & 511 & 511 & 515 & 515 \\
\hline \multicolumn{6}{|l|}{ Panel C: Women older than 21} \\
\hline Treat $\times$ power outage intensity & $\begin{array}{l}0.132 * * \\
(0.065)\end{array}$ & $\begin{array}{l}0.105^{*} \\
(0.060)\end{array}$ & $\begin{array}{l}0.106^{*} \\
(0.060)\end{array}$ & $\begin{array}{l}0.110^{*} \\
(0.059)\end{array}$ & $\begin{array}{l}0.141 * * \\
(0.065)\end{array}$ \\
\hline Municipality FE & & Yes & Yes & & \\
\hline Birth year cohort FE & & & Yes & & \\
\hline Municipality $\times$ birth year FE & & & & Yes & Yes \\
\hline Region $\times$ treatment & & & & & Yes \\
\hline Mean number of births & 2.81 & 2.81 & 2.81 & 2.81 & 2.81 \\
\hline Women & 44456 & 44456 & 44456 & 44456 & 44456 \\
\hline Clusters & 515 & 515 & 515 & 515 & 515 \\
\hline
\end{tabular}

Notes: Significance levels are indicated as *0.10, **0.05, and ***0.01. Standard errors (in parentheses) are clustered at the municipality level. Power outage is a dummy variable equal to one if a municipality experienced above median power rationing in 1992. Treated is an indicator equal to one for births occurring in the treatment time window as defined in Fig. 5. The dependent variable in panel A is the total number of births since 1990. The dependent variable in panel B is the time gap in months since the last birth, thus restricting the analysis to the set of mothers in the treatment and control group who had already a child prior to treatment 
Table 12 Continuous outage measure: birth spacing: number of months passed since previous birth
(1)
(2)
(3)
(4)
(5)

Panel A: All women

\begin{tabular}{|c|c|c|c|c|c|}
\hline Treat $\times$ power outage intensity & $\begin{array}{r}-1.431 \\
(1.628)\end{array}$ & $\begin{array}{r}-1.328 \\
(1.624)\end{array}$ & $\begin{array}{r}-1.902 \\
(1.378)\end{array}$ & $\begin{array}{r}-1.205 \\
(1.623)\end{array}$ & $\begin{array}{r}-1.732 \\
(1.802)\end{array}$ \\
\hline Municipality FE & & Yes & Yes & & \\
\hline Birth year cohort FE & & & Yes & & \\
\hline Municipality $\times$ birth year FE & & & & Yes & Yes \\
\hline Region $\times$ treatment & & & & & Yes \\
\hline Average months between births & 48.1 & 48.1 & 48.1 & 48.1 & 48.1 \\
\hline Women & 32297 & 32297 & 32297 & 32297 & 32297 \\
\hline Clusters & 515 & 515 & 515 & 515 & 515 \\
\hline \multicolumn{6}{|l|}{ Panel B: Women younger than 21} \\
\hline Treat $\times$ power outage intensity & $\begin{array}{r}-2.713 \\
(1.857)\end{array}$ & $\begin{array}{r}-2.956 \\
(1.837)\end{array}$ & $\begin{array}{r}-2.736 \\
(1.788)\end{array}$ & $\begin{array}{r}-2.466 \\
(2.060)\end{array}$ & $\begin{array}{r}-3.413 \\
(2.161)\end{array}$ \\
\hline Municipality FE & & Yes & Yes & & \\
\hline Birth year cohort FE & & & Yes & & \\
\hline Municipality $\times$ birth year FE & & & & Yes & Yes \\
\hline Region $\times$ treatment & & & & & Yes \\
\hline Average months between births & 28.8 & 28.8 & 28.8 & 28.8 & 28.8 \\
\hline Women & 4863 & 4830 & 4830 & 4863 & 4863 \\
\hline Clusters & 489 & 456 & 456 & 489 & 489 \\
\hline \multicolumn{6}{|l|}{ Panel C: Women older than 21} \\
\hline Treat $\times$ power outage intensity & $\begin{array}{r}-1.295 \\
(1.850)\end{array}$ & $\begin{array}{r}-0.734 \\
(1.831)\end{array}$ & $\begin{array}{r}-1.557 \\
(1.593)\end{array}$ & $\begin{array}{r}-1.011 \\
(1.810)\end{array}$ & $\begin{array}{r}-1.461 \\
(2.022)\end{array}$ \\
\hline Municipality FE & & Yes & Yes & & \\
\hline Birth year cohort FE & & & Yes & & \\
\hline Municipality $\times$ birth year FE & & & & Yes & Yes \\
\hline Region $\times$ treatment & & & & & Yes \\
\hline Average months between births & 51.5 & 51.5 & 51.5 & 51.5 & 51.5 \\
\hline Women & 27434 & 27433 & 27433 & 27434 & 27434 \\
\hline Clusters & 515 & 514 & 514 & 515 & 515 \\
\hline
\end{tabular}

Notes: Significance levels are indicated as $* 0.10, * * 0.05$, and $* * * 0.01$. Standard errors (in parentheses) are clustered at the municipality level. Power outage is a dummy variable equal to one if a municipality experienced above median power rationing in 1992. Treated is an indicator equal to one for births occurring in the treatment time window as defined in Fig. 5. The dependent variable is the time gap in months since the last birth, thus restricting the analysis to the set of mothers in the treatment and control group who had already a child prior to treatment 
Table 13 Continuous outage measure birth spacing: number of months passed to the next birth
(1)
(2)
(3)
(4)
(5)

Panel A: All women

\begin{tabular}{|c|c|c|c|c|c|}
\hline Treat $\times$ power outage intensity & $\begin{array}{r}-0.599 \\
(1.564)\end{array}$ & $\begin{array}{r}-0.632 \\
(1.552)\end{array}$ & $\begin{array}{r}-0.680 \\
(1.554)\end{array}$ & $\begin{array}{r}-0.444 \\
(1.859)\end{array}$ & $\begin{array}{c}0.640 \\
(1.988)\end{array}$ \\
\hline Municipality FE & & Yes & Yes & & \\
\hline Birth year cohort FE & & & Yes & & \\
\hline Municipality $\times$ birth year FE & & & & Yes & Yes \\
\hline Region $\times$ treatment & & & & & Yes \\
\hline Average months between births & 50.9 & 50.9 & 50.9 & 50.9 & 50.9 \\
\hline Women & 36744 & 36744 & 36744 & 36744 & 36744 \\
\hline Clusters & 515 & 515 & 515 & 515 & 515 \\
\hline \multicolumn{6}{|l|}{ Panel B: Women younger than 21} \\
\hline Treat $\times$ power outage intensity & $\begin{array}{r}-1.098 \\
(2.417)\end{array}$ & $\begin{array}{r}-1.830 \\
(2.400)\end{array}$ & $\begin{array}{r}-1.939 \\
(2.398)\end{array}$ & $\begin{array}{r}-0.749 \\
(2.806)\end{array}$ & $\begin{array}{c}0.533 \\
(3.178)\end{array}$ \\
\hline Municipality FE & & Yes & Yes & & \\
\hline Birth year cohort FE & & & Yes & & \\
\hline Municipality $\times$ birth year FE & & & & Yes & Yes \\
\hline Region $\times$ treatment & & & & & Yes \\
\hline Average months between births & 50.6 & 50.6 & 50.6 & 50.6 & 50.6 \\
\hline Women & 14127 & 14119 & 14119 & 14127 & 14127 \\
\hline Clusters & 515 & 507 & 507 & 515 & 515 \\
\hline
\end{tabular}

Panel C: Women older than 21

Treat $\times$ power outage intensity

$\begin{array}{clll}0.060 & 0.615 & 0.606 & -0.288 \\ (1.845) & (1.852) & (1.867) & (2.208) \\ & \text { Yes } & \text { Yes } & \\ & & \text { Yes } & \end{array}$

0.782

Municipality FE

Birth year cohort FE

Municipality $\times$ birth year FE

Region $\times$ treatment

Average months between births

Women

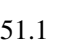

51.1

Clusters

22617

51.1

51.1

Yes

Yes

Yes

514

22617

22617

51.1

51.1

514

514

22617

22617

Notes: Significance levels are indicated as $* 0.10, * * 0.05$, and $* * * 0.01$. Standard errors (in parentheses) are clustered at the municipality level. Power outage is a dummy variable equal to one if a municipality experienced above median power rationing in 1992. Treated is an indicator equal to one for births occurring in the treatment time window as defined in Fig. 5. The dependent variable is the time gap in months to the next birth 


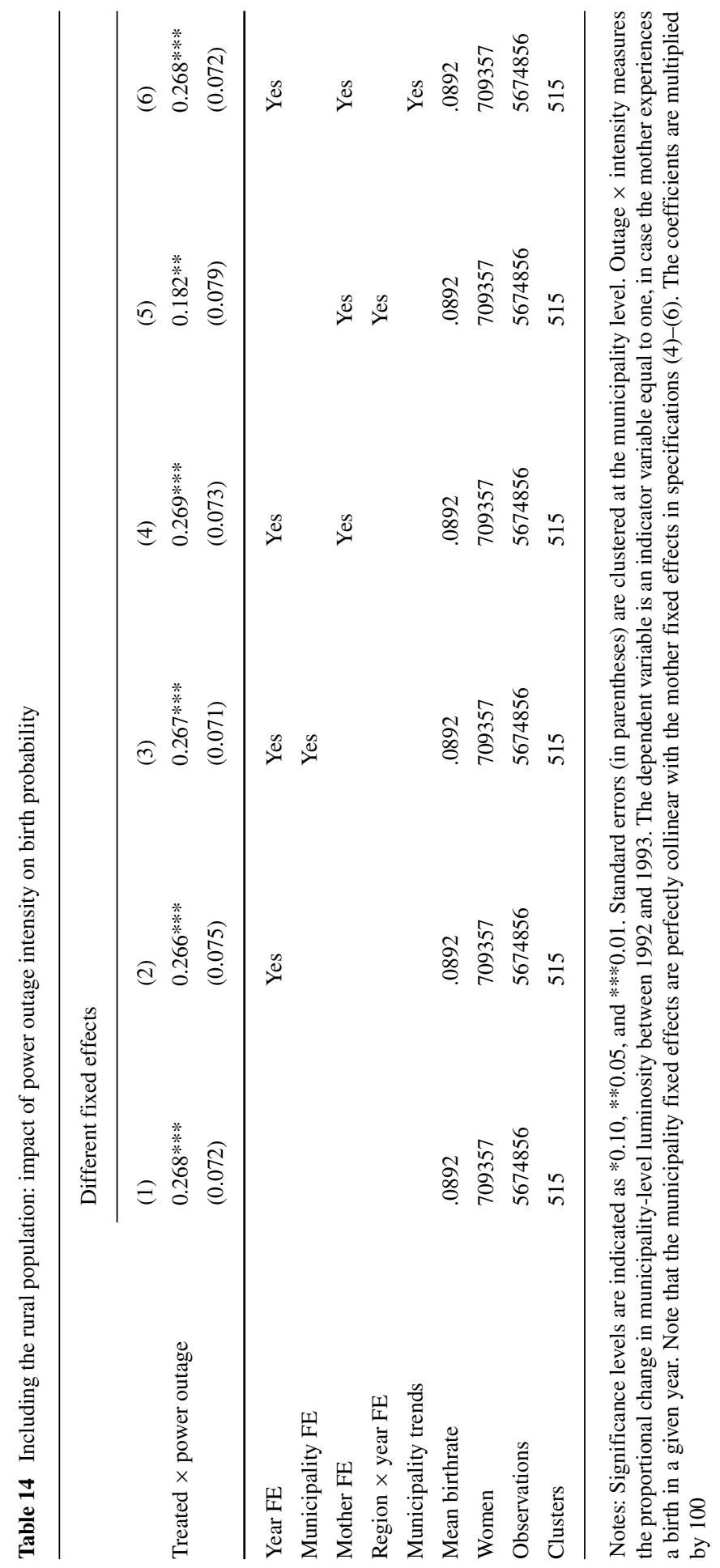


Table 15 Including rural population: long run fertility effect overall and by age group
(1)
(2)
(3)
(4)
(5)

Panel A: All women

Treat $\times$ power outage

$\begin{array}{lllll}0.069 * * * & 0.068 * * * & 0.067 * * * & 0.062 * * * & 0.048 * * \\ (0.023) & (0.020) & (0.020) & (0.021) & (0.023)\end{array}$

Municipality FE

Birth year cohort FE

Municipality $\times$ birth year FE

Region $\times$ treatment

Mean number of dependent variable

Women

107879

3.15

Yes

Yes

Yes

Clusters

515

107879

515

107879

15

Panel B: Women younger than 21

Treat $\times$ power outage

$\begin{array}{lllll}0.073 * & 0.072 * * & 0.070 * & 0.086 * * & 0.066 * \\ (0.041) & (0.036) & (0.036) & (0.037) & (0.040) \\ & \text { Yes } & \text { Yes } & & \end{array}$

Municipality FE

Birth year cohort FE

Municipality $\times$ birth year FE

Region $\times$ treatment

Mean number of dependent variable

Women

31946

3.09

Yes

Yes $\quad$ Yes

Clusters

515

515

3.09

Panel C: Women older than 21

Treat $\times$ power outage

$0.077 * * *$
$(0.026)$

$0.067 * * *$

$0.068 * * *$

$0.053 * *$

0.041

Municipality FE

Birth year cohort FE

Municipality $\times$ birth year FE

Region $\times$ treatment

Mean number of dependent variable

(0.024)

Women

3.18
75933
515

Yes

Yes

Yes

Clusters

515

3.18
75933
515

3.18
75933
515

Yes

Yes

Yes

3.18

3.18

75933

Notes: Significance levels are indicated as *0.10, **0.05, and ***0.01. Standard errors (in parentheses) are clustered at the municipality level. Power outage is a dummy variable equal to one if a municipality experienced above median power rationing in 1992. Treated is an indicator equal to one for births occurring in the treatment time window as defined in Fig. 5. The dependent variable in panel $\mathrm{A}$ is the total number of births since 1990. The dependent variable in panel B is the time gap in months since the last birth, thus restricting the analysis to the set of mothers in the treatment and control group who had already a child prior to treatment 
Table 16 Including rural population: birth spacing: number of months passed since previous birth
(1)
(2)
(3)
(4)
(5)

Panel A: All women

Treat $\times$ power outage

$$
\begin{array}{rrrrr}
-0.130 & -0.280 & -0.762 & -1.143^{* *} & -1.108 * \\
(0.583) & (0.591) & (0.526) & (0.542) & (0.622)
\end{array}
$$

Municipality FE

Birth year cohort FE

Municipality $\times$ birth year FE

Region $\times$ treatment

Average months between births

Women

Clusters

Panel B: Women younger than 21

Treat $\times$ power outage

Municipality FE

Birth year cohort FE

Municipality $\times$ birth year FE

Region $\times$ treatment

Average months between births

Women

Clusters

Panel C: Women older than 21

Treat $\times$ power outage

Municipality FE

Birth year cohort FE

Municipality $\times$ birth year FE

Region $\times$ treatment

Average months between births

Women

Clusters

$\begin{array}{cc}\text { Yes } & \text { Yes } \\ & \text { Yes }\end{array}$

59396

44.9

44.9

Yes

515

59396

59396

44.9

Yes

515

515

59396

44.9

59396

515

$\begin{array}{ccccc}0.538 & 0.299 & 0.344 & 0.143 & 0.193 \\ (0.576) & (0.567) & (0.558) & (0.658) & (0.680) \\ & \text { Yes } & \text { Yes } & & \\ & & \text { Yes } & & \end{array}$

$\begin{array}{lllll} & & & \text { Yes } & \text { Yes } \\ & & & \text { Yes } \\ 28.1 & 28.1 & 28.1 & 28.1 & 28.1 \\ 9541 & 9541 & 9541 & 9541 & 9541 \\ 514 & 514 & 514 & 514 & 514\end{array}$

$\begin{array}{lllll}-0.473 & -0.451 & -0.986 & -1.349 * * & -1.303^{*} \\ (0.683) & (0.689) & (0.614) & (0.626) & (0.714) \\ & \text { Yes } & \text { Yes } & & \\ & & \text { Yes } & & \\ & & & \text { Yes } & \text { Yes } \\ & & & & \text { Yes } \\ 48.1 & 48.1 & 48.1 & 48.1 & 48.1 \\ 49855 & 49855 & 49855 & 49855 & 49855 \\ 515 & 515 & 515 & 515 & 515\end{array}$

Notes: Significance levels are indicated as $* 0.10, * * 0.05$, and $* * * 0.01$. Standard errors (in parentheses) are clustered at the municipality level. Power outage is a dummy variable equal to one if a municipality experienced above median power rationing in 1992. Treated is an indicator equal to one for births occurring in the treatment time window as defined in Fig. 5. The dependent variable is the time gap in months since the last birth, thus restricting the analysis to the set of mothers in the treatment and control groups who had already a child prior to treatment 
Table 17 Including rural population: birth spacing: number of months passed to the next birth
(1)
(2)
(3)
(4)
(5)

Panel A: All women

Treat $\times$ power outage

$\begin{array}{ccccc}0.220 & 0.176 & 0.137 & 0.081 & 0.559 \\ (0.531) & (0.530) & (0.525) & (0.586) & (0.616)\end{array}$

Municipality FE

$\begin{array}{ll}\text { Yes } & \text { Yes } \\ & \text { Yes }\end{array}$

Birth year cohort FE

Municipality $\times$ birth year FE

Region $\times$ treatment

Average months between births

Women

Clusters

Panel B: Women younger than 21

Treat $\times$ power outage

$\begin{array}{lllll} & & & \text { Yes } & \text { Yes } \\ & & & \text { Yes } \\ 47.6 & 47.6 & 47.6 & 47.6 & 47.6 \\ 68942 & 68942 & 68942 & 68942 & 68942 \\ 515 & 515 & 515 & 515 & 515\end{array}$

Municipality FE

Birth year cohort FE

Municipality $\times$ birth year FE

Region $\times$ treatment

Average months between births

$\begin{array}{ccccc}0.017 & -0.473 & -0.512 & -0.461 & 0.564 \\ (0.885) & (0.841) & (0.847) & (0.914) & (0.936) \\ & \text { Yes } & \text { Yes } & & \\ & & \text { Yes } & & \end{array}$

Women

$\begin{array}{ll}47.1 & 47.1 \\ 26369 & 26369 \\ 515 & 515\end{array}$

47.1

Yes

Yes

Clusters

Panel C: Women older than 21

Treat $\times$ power outage

$\begin{array}{lllll}0.444 & 0.607 & 0.605 & 0.412 & 0.549 \\ (0.662) & (0.657) & (0.653) & (0.772) & (0.742) \\ & \text { Yes } & \text { Yes } & & \\ & & \text { Yes } & & \\ & & & \text { Yes } & \text { Yes } \\ & & & & \text { Yes } \\ 47.9 & 47.9 & 47.9 & 47.9 & 47.9 \\ 42573 & 42573 & 42573 & 42573 & 42573 \\ 515 & 515 & 515 & 515 & 515\end{array}$

Municipality FE

Birth year cohort FE

Municipality $\times$ birth year FE

Region $\times$ treatment

Average months between births

Women

Clusters

26369

47.1

47.1

26369

26369

26369

515

515

515

Notes: Significance levels are indicated as $* 0.10, * * 0.05$, and $* * * 0.01$. Standard errors (in parentheses) are clustered at the municipality level. Power outage is a dummy variable equal to one if a municipality experienced above median power rationing in 1992. Treated is an indicator equal to one for births occurring in the treatment time window as defined in Fig. 5. The dependent variable is the time gap in months to the next birth 


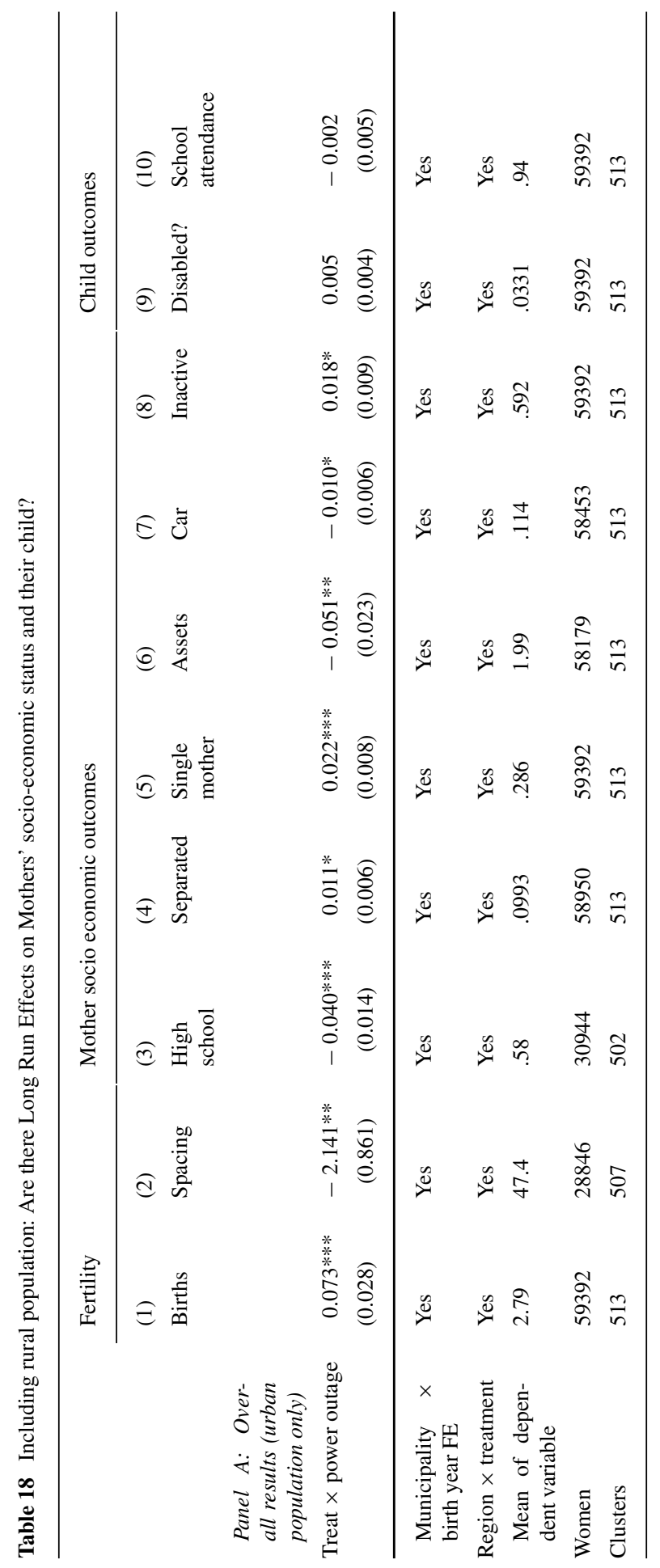




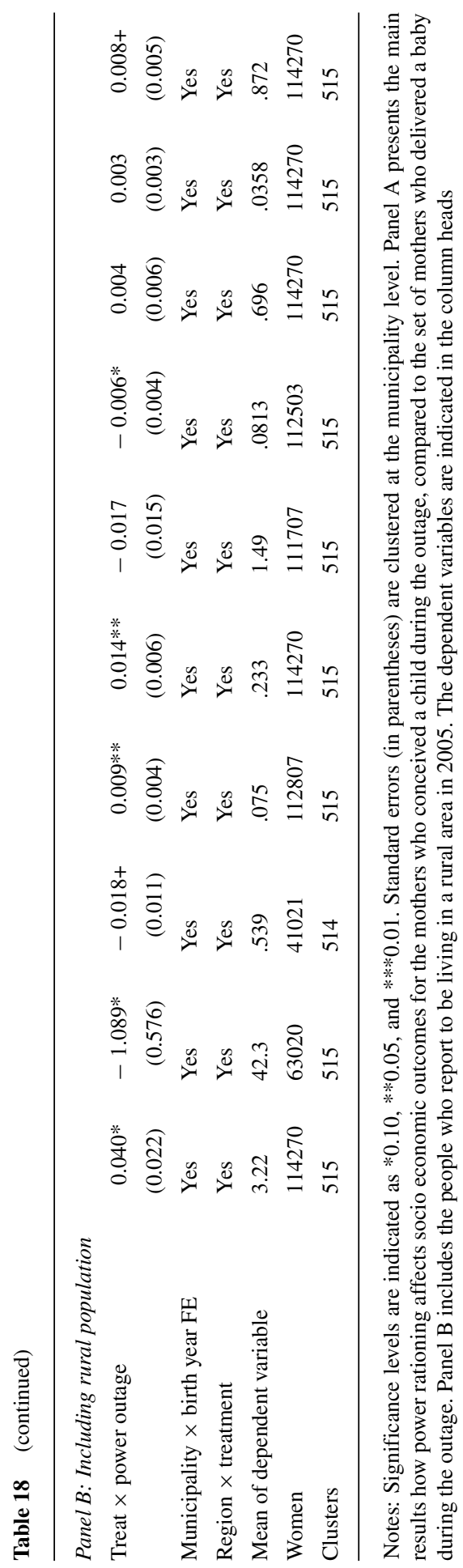


Table 19 Using the census measure of number of children: long run fertility effect overall and by age group
(1)
(2)
(3)
(4)
(5)

Panel A: All women

Treat $\times$ power outage

$\begin{array}{lllll}0.071^{* * *} & 0.070^{* * * *} & 0.070^{* * *} & 0.071^{* * *} & 0.078^{* * *} \\ (0.027) & (0.025) & (0.025) & (0.026) & (0.028)\end{array}$

Municipality FE

Birth year cohort FE

Municipality $\times$ birth year FE

Region $\times$ treatment

Mean of dependent variable

Women

62318

Yes

Yes

Clusters

515

Yes

Panel B: Women younger than 21

Treat $\times$ power outage

$\begin{array}{lllll}0.086^{*} & 0.101^{* *} & 0.100^{* *} & 0.104^{* *} & 0.106^{*} \\ (0.050) & (0.046) & (0.046) & (0.051) & (0.056) \\ & \text { Yes } & \text { Yes } & & \\ & & \text { Yes } & & \\ & & & \text { Yes } & \text { Yes } \\ & & & & \text { Yes } \\ 2.87 & 2.87 & 2.87 & 2.87 & 2.87 \\ 17862 & 17858 & 17858 & 17862 & 17862 \\ 515 & 511 & 511 & 515 & 515\end{array}$

Panel C: Women older than 21

Treat $\times$ power outage

$\begin{array}{lllll}0.069^{* *} & 0.056^{* *} & 0.056^{* *} & 0.061^{* *} & 0.070^{* *} \\ (0.030) & (0.028) & (0.028) & (0.029) & (0.031) \\ & \text { Yes } & \text { Yes } & & \\ & & \text { Yes } & & \\ & & & \text { Yes } & \text { Yes } \\ & & & & \text { Yes } \\ 2.84 & 2.84 & 2.84 & 2.84 & 2.84 \\ 44456 & 44456 & 44456 & 44456 & 44456 \\ 515 & 515 & 515 & 515 & 515\end{array}$

Municipality FE

Birth year cohort FE

Municipality $\times$ birth year FE

Region $\times$ treatment

Mean of dependent variable

Women

62318

2.85

Yes

Yes

Municipality FE

Birth year cohort FE

Region $\times$ treatment

Mean of dependent variable

Women

62318

62318

2.85

2.85

515

62318

62318

515

515

Clusters

515

515

Notes: Significance levels are indicated as $* 0.10, * * 0.05$, and $* * * 0.01$. Standard errors (in parentheses) are clustered at the municipality level. Power outage is a dummy variable equal to one if a municipality experienced above median power rationing in 1992. Treated is an indicator equal to one for births occurring in the treatment time window as defined in Fig. 5. The dependent variable in panel A is the total number of births since 1990. The dependent variable in panel B is the time gap in months since the last birth, thus restricting the analysis to the set of mothers in the treatment and control groups who had already a child prior to treatment 
Table 20 Birth spacing: number of months passed to the next birth
(1)
(2)
(3)
(4)
(5)

Panel A: All women

Treat $\times$ power outage

$\begin{array}{ccccc}0.549 & 0.499 & 0.472 & 0.610 & 1.432 \\ (0.780) & (0.771) & (0.764) & (0.900) & (0.961)\end{array}$

Municipality FE

Yes

Yes

Birth year cohort FE

Municipality $\times$ birth year FE

Region $\times$ treatment

Average months between births

Women

36744

Yes

Clusters

515

515

36744

50.9

Panel B: Women younger than 21

Treat $\times$ power outage

$\begin{array}{cccc}-0.268 & -0.828 & -0.882 & -0.450 \\ (1.261) & (1.232) & (1.242) & (1.439) \\ & \text { Yes } & \text { Yes } & \\ & & \text { Yes } & \end{array}$

Municipality FE

Birth year cohort FE

Municipality $\times$ birth year FE

Region $\times$ treatment

Average months between births

Women

14127

50.6

Yes

Yes

Yes

Clusters

14119

50.6

50.6

50.6

Panel C: Women older than 21

Treat $\times$ power outage

507

14119

507

Municipality FE

Birth year cohort FE

Municipality $\times$ birth year FE

Region $\times$ treatment

Average months between births

(0.924)

(1.126)

Yes

Yes

Yes

Women

51.1

51.1

51.1

Yes

Yes

Yes

Clusters

22617

22617

22617

51.1

51.1

514

514

514

Notes: Significance levels are indicated as $* 0.10, * * 0.05$, and $* * * 0.01$. Standard errors (in parentheses) are clustered at the municipality level. Power outage is a dummy variable equal to one if a municipality experienced above median power rationing in 1992. Treated is an indicator equal to one for births occurring in the treatment time window as defined in Fig. 5. The dependent variable is the time gap in months to the next birth 
Table 21 Restricting to non-mover sample: long-run fertility and birth spacing effects
(1)
(2)
(3)
(4)
(5)

Panel A: Overall fertility

\begin{tabular}{llcccc} 
Treat $\times$ power outage & $\begin{array}{c}0.056 * * \\
(0.025)\end{array}$ & $\begin{array}{c}0.056^{* *} \\
(0.023)\end{array}$ & $\begin{array}{c}0.057 * * \\
(0.023)\end{array}$ & $\begin{array}{c}0.059 * * \\
(0.024)\end{array}$ & $\begin{array}{c}0.064 * * \\
(0.026)\end{array}$ \\
\hline $\begin{array}{l}\text { Municipality FE } \\
\text { Birth year cohort FE }\end{array}$ & \multicolumn{2}{c}{ Yes } & Yes & & \\
Municipality $\times$ birth year FE & & & Yes & Yes & Yes \\
Region $\times$ treatment & & & & Yes \\
Mean of dependent variable & 2.87 & 2.87 & 2.87 & 2.87 & 2.87 \\
Women & 34644 & 34643 & 34643 & 34644 & 34644 \\
Clusters & 515 & 514 & 514 & 515 & 515
\end{tabular}

Panel B: Time from previous birth

\begin{tabular}{|c|c|c|c|c|c|}
\hline Treat $\times$ power outage & $\begin{array}{c}0.088 \\
(1.091)\end{array}$ & $\begin{array}{c}0.097 \\
(1.054)\end{array}$ & $\begin{array}{r}-0.211 \\
(0.989)\end{array}$ & $\begin{array}{r}-2.154^{*} \\
(1.123)\end{array}$ & $\begin{array}{r}-2.118^{*} \\
(1.224)\end{array}$ \\
\hline Municipality FE & & Yes & Yes & & \\
\hline Birth year cohort FE & & & Yes & & \\
\hline Municipality $\times$ birth year FE & & & & Yes & Yes \\
\hline Region $\times$ treatment & & & & & Yes \\
\hline Average months between births & 46.2 & 46.2 & 46.2 & 46.2 & 46.2 \\
\hline Women & 17747 & 17742 & 17742 & 17747 & 17747 \\
\hline Clusters & 513 & 508 & 508 & 513 & 513 \\
\hline \multicolumn{6}{|l|}{ Panel C: Time to subsequent birth } \\
\hline \multirow[t]{2}{*}{ Treat $\times$ power outage } & 0.245 & 0.229 & 0.183 & 0.813 & 0.537 \\
\hline & $(0.901)$ & $(0.911)$ & $(0.908)$ & $(1.123)$ & $(1.219)$ \\
\hline Municipality FE & & Yes & Yes & & \\
\hline Birth year cohort FE & & & Yes & & \\
\hline Municipality $\times$ birth year FE & & & & Yes & Yes \\
\hline Region $\times$ treatment & & & & & Yes \\
\hline Average months between births & 48.7 & 48.7 & 48.7 & 48.7 & 48.7 \\
\hline Women & 21137 & 21136 & 21136 & 21137 & 21137 \\
\hline Clusters & 513 & 512 & 512 & 513 & 513 \\
\hline
\end{tabular}

Notes: Significance levels are indicated as $* 0.10, * * 0.05$, and $* * * 0.01$. Standard errors (in parentheses) are clustered at the municipality level. Power outage is a dummy variable equal to one if a municipality experienced above median power rationing in 1992. Treated is an indicator equal to one for births occurring in the treatment time window. The dependent variable is the overall number of children born to a mother in in panel $\mathrm{A}$, the time from the previous birth in panel $\mathrm{B}$ and the time to the subsequent birth in panel $\mathrm{C}$ measured in months 


\section{References}

Angrist JD, Evans WN (1998) Children and their parents' labor supply: evidence from exogenous variation in family size. Amer Econ Rev 88(3):450-477

Aragón FM, Rud J (2016) Air pollution and infant mortality: evidence from a million births. mimeo

Ashcraft A, Fernández-Val I, Lang K (2013) The consequences of teenage childbearing: consistent estimates when abortion makes miscarriage nonrandom. Econ J 123(571):875-905

Barmby T, Cigno A (1990) A sequential probability model of fertility patterns. J Popul Econ 31(3):365386

Black SE, Devereux PJ, Salvanes KG (2005) Why the apple doesn't fall far: understanding intergenerational transmission of human capital. Amer Econ Rev 95(1):437-449

Bozzoli C, Deaton A, Quintana-Domeque C (2009) Adult height and childhood disease. Demography 46(4):647-669

Bozzoli C, Quintana-Domeque C (2014) The weight of the crisis: evidence from newborns in argentina. Rev Econ Stat 96(3):550-562

Burlando A (2014a) Power outages, power externalities, and baby booms. Demography 51(4):1477-500

Burlando A (2014b) Transitory shocks and birth weights: evidence from a blackout in Zanzibar. J Dev Econ 108:154-168

Chen XK, Wen SW, Fleming N, Demissie K, Rhoads GG, Walker M (2007) Teenage pregnancy and adverse birth outcomes: a large population based retrospective cohort study. Int J Epidemiol 36(2):368-373

Clarke D, Oreffice S, Quintana-Domeque C (2016) The demand for season of birth

Deichmann U, Henderson J, Storeygard A (2014) Is climate change driving urbanization in Africa?

Dinkelman T (2011) The effects of rural electrification on employment: new evidence from South Africa. Amer Econ Rev 101(December):3078-3108

Doll C (2008) CIESIN thematic guide to night-time light remote sensing and its applications. Earth Sci Inf Netw C:1-41

Elvidge CD, Baugh KE, Kihn EA, Kroehl HW, Davis ER, Davis CW (1997) Relation between satellite observed visible-near infrared emissions, population, economic activity and electric power consumption. Int J Remote Sens 18(6):1373-1379

Elvidge CD, Safran J, Nelson IL, Tuttle BT, Hobson VR, Baugh KE, Dietz JB, Erwin EH (2004) Area and positional accuracy of DMSP nighttime lights data, CRC Press, Hoboken

Evans RW, Hu Y, Zhao Z (2008) The fertility effect of catastrophe: U.S. hurricane births. J Popul Econ 23(1):1-36

Ferrara E, Chong A, Duryea S (2012) Soap operas and fertility: evidence from Brazil. Amer Econ J: Appl Econ 4(4):1-31

Fetzer T, Henderson V, Nigmatulina D, Shanghavi A (2016) What happens to cities when countries democratize? mimeo

Fisher-Vanden K, Mansur ET, Wang QJ (2015) Electricity shortages and firm productivity: evidence from China's industrial firms. J Dev Econ 114:172-188

Gerard F, Costa FJM (2015) Hysteresis and the social cost of corrective policies: evidence from a temporary energy saving program. mimeo

Geronimus AT, Korenman S (1993) The socioeconomic costs of teenage childbearing: evidence and interpretation. Demography 30(2):281-290. Discussion 291-296

Henderson JV, Storeygard A, Weil DN (2012) Measuring economic growth from outer space. Amer Econ Rev 102(2):994-1028

Hodler R, Raschky PA (2014) Regional favoritism. Q J Econ 129(2):995-1033

Gangadharan J, Rosenbloom J, Jacobson J, Pearre JW III (1999) The effects of childbearing on married women's labor supply and earnings: using twin births as a natural experiment. J Human Res 34(3):449-474

Jensen R, Oster E (2009) The power of TV: cable television and women's status in india. Q J Econ 124(3):1057-1094

Jiang B, Yin J, Liu Q (2014) Zipf's law for all the natural cities around the world. mimeo

Kearney MS, Levine PB (2015) Media influences on social outcomes: the impact of MTV's 16 and pregnant on teen childbearing. Amer Econ Rev 105(12):3597-3632

Michalopoulos S, Papaioannou E (2013) Pre-colonial ethnic institutions and contemporary african development. Econometrica 81(1):113-152 
Oliveira VHD, Quintana-Domeque C (2016) Natural disasters and early human development: hurricane Catarina and birth outcomes in Brazil. mimeo

Pörtner C (2008) Gone with the wind? hurricane risk, fertility and education. mimeo

Proville J, Zavala-Araiza D, Wagner G (2017) Night-time lights: a global, long term look at links to socio-economic trends. PLoS ONE 12(3):1-12

Quintana-Domeque C, Ródenas-Serrano P (2014) Terrorism and human capital at birth: bomb casualties and birth outcomes in Spain. IZA Discussion Paper

Reinikka R, Svensson J (2002) Coping with poor public capital. J Dev Econ 69(1):51-69

Ribar D (1994) Teenage fertility and high school completion. Rev Econ Stat 3(3):413-424

Ribar DC (1999) The socioeconomic consequences of young women's childbearing: reconciling disparate evidence. J Popul Econ 12(4):547-565

Rud J (2012) Electricity provision and industrial development: evidence from India. Journal of Development Economics 97(2):1-36

Schindler K, Brück T. (2011) The effects of conflict on fertility in rwanda. DIW Discussion Papers:1143

Storeygard A (2015) Farther on down the road: transport costs, trade and urban growth in sub-Saharan Africa. forthcoming, Review of Economic Studies

Udry JR (1970) The effect of the great blackout of 1965 on births in new york city. Demography 7(3):325327

Ward MP, Butz WP (1980) Completed fertility and its timing. J Polit Econ 88(5):917

WHO (2010) World Health Statistics 2010. Technical report, World Health Organization, Geneva 